\title{
Role of Environmental and Inflammatory Toxicity in Neuronal Cell Death
}

\author{
Mallika Somayajulu-Niţu ${ }^{1}$, Danijela Domazet-Damjanov ${ }^{1}$, Anca Matei ${ }^{1}$, Edward Schwartzenberger ${ }^{1}$, \\ Jerome Cohen ${ }^{2}$ and Siyaram Pandey ${ }^{1, *}$
}

${ }^{I}$ Department of Chemistry and Biochemistry and ${ }^{2}$ Department of Psychology, University of Windsor, Windsor, ON,
Canada

\begin{abstract}
Neuronal cells are exclusively dependent on oxidative phosphorylation for energy and are under constant threat of oxidative damage due to mitochondrial production of reactive oxygen species by partial reduction of molecular oxygen. These cells also have a multitude of antioxidative defense mechanisms, but there is a slow decline of antioxidative defence capacity with aging. The result is the increased vulnerability of cells to oxidative stress, particularly neuronal cells. Any environmental, inflammatory or psychological stress that can topple the redox balance will eventually lead to oxidative stress and neuronal cell death. Indeed, cell death induced by oxidative stress has been implicated in age-related loss of neurons during normal aging and several neurodegenerative disorders. It is critical to understand the mechanisms by which different risk factors lead to neuronal cell death in order to identify pathways involved in neurodegenerative diseases. In this review we focus on the implications of various factors such as environmental toxins, drugs and psychological stress in neurodegenerative diseases with specific focus on Parkinson's disease and Alzheimer's disease. Here we highlight the recent progress that supports the role of molecular mechanisms of oxidative stress, neuroinflammation and mitochondrial dysfunction as contributors to neurotoxicity and research on developing therapeutics that could potentially slow down the progression of neurodegeneration.
\end{abstract}

Key Words: Alzheimer's disease, Parkinson's disease, oxidative stress, herbicide and pesticides neurotoxicity.

\section{PARKINSON'S DISEASE (PD)}

\subsection{Introduction}

Parkinson's disease is the second most common agerelated neurodegenerative disease [1]. It is characterized by a progressive degeneration of dopaminergic (DA) neurons in the substantia nigra pars compacta that project into the striatum. The dopamine neurons play an important role in coordinating normal motor function. Clinical symptoms such as resting tremors, bradykinesia, rigidity and postural instability arise when about $60-70 \%$ of the DA neurons are lost, leading to a decline in the dopamine levels in the nigrostriatal pathway [2]. The pathological hallmark of the disease is the formation of Lewy bodies in the cytoplasm of degenerating DA neurons of the substantia nigra (SN) [3]. In general, PD is a sporadic disease, with less than $5 \%$ of PD cases being attributed to genetic causes [4]. There is much evidence that increasingly points towards correlation of PD to the exposure to environmental toxins. First, a study by Tanner et al. [5] screened 19,000 monozygotic and dizogotic twins for PD and found that there were very similar concordance rates between the two types of twins. This result led Tanner to conclude that "genetic factors do not play a major role in causing typical PD." Second, rates of PD vary geographically. In most cases, PD occurs in a greater frequency in industrialized nations. In China, an increased risk of PD was

*Address correspondence to this author at the Chemistry and Biochemistry, University of Windsor, Windsor, ON N9B 3P4, Canada; Tel: (519) 2533000, Ex: 3701; Fax: (519) 973-7098; E-mail: spandey@uwindsor.ca correlated with exposure to industrial chemicals, printing plants or quarries [6]. Additionally, between 1984 and 1994 in California, a state which uses almost a quarter of all pesticides in the US, a higher rate of PD was found in counties using agricultural pesticides [7]. A number of risk factors have been linked to PD; however, PD is not caused as a result of any one factor, but instead a combination of environmental factors and genetic susceptibility.

\subsection{Selective Vulnerability of Dopaminergic Neurons in PD}

It has progressively become apparent that susceptibility of neurons in PD extends further than the SN region, and in addition, includes particular neurons in the autonomic ganglia, basal forebrain, limbic lobe, brainstem and neocortex $[8,9]$. Interestingly, the most pertinent clinical condition remains to be the loss of the neurons in the nigrostriatal pathway. The vulnerability of SN neurons in PD may be explained by the propensity of dopamine and its metabolites to produce reactive oxygen species (ROS) $[9,10]$. There have been several suggestions to explain the selective loss of DA neurons in PD, but to date, there has been no reasonable exposition for the susceptibility of other neuronal populations.

\subsection{Drug Exposure as a Risk for PD}

MPTP (1-methyl-4-phenyl-1,2,3,6-tetrahydropyridine), a by-product of the production of synthetic heroin and an analogue of meperidine, has a very high selectivity for SN cells. It is one of the well-studied neurotoxins. Its potency in trig- 
gering PD was discovered accidentally in 1982, in a group of people who consumed synthetic heroin. Although young, these individuals developed Parkinsonian symptoms [11]. With the exception of Lewy bodies, neuropathological, clinical as well as biochemical characteristics observed in these individuals matched the symptoms of PD [11]. MPTP has been used to induce PD in animal models in order to elucidate the mechanism of the degeneration of the nigrostriatal pathway. It has been shown that the vulnerability of the nigrostriatal degeneration to MPTP is amplified with increasing age [12]. MPTP is a very lipophilic compound and after crossing the blood brain barrier upon administration, it is converted to its toxic metabolite 1-methyl-4-phenyl pyridinium ion $\left(\mathrm{MPP}^{+}\right)$by monoamine oxidase $\mathrm{B}$ especially in non-dopaminergic cells such as astrocytes and serotonergic neurons $[1,12,13] . \mathrm{MPP}^{+}$is a substrate for both the vesicular monoamine transporter as well as the dopamine transporter present on the DA neurons $[14,15]$. $\mathrm{MPP}^{+}$accumulates in the mitochondria of the dopaminergic cells and inhibits complex-I of the electron transport chain [16]. It has also been show to cause neuroinflammation [17], further adding to its pathological role in PD. Systemic MPTP administration in mice induces PD-like symptoms, including bradykinesia, rigidity, and posture anomalies. These symptoms parallel the low dopamine neuron counts that also result due to MPTP exposure [18]. MPTP induces the symptoms of PD in rodents, as well as in cats, non-human primates, and mini-pigs [19]. Several studies have also investigated the role of MPTP on motor behaviour, including locomotion, circling, rearing, or stereotyped behaviour.

\subsection{Environmental Factors and the Risk of PD}

Although the most prominent risk factor for PD is age, studies have pointed towards the interplay between both genetic and environmental factors. Several epidemiological studies have revealed a link between environmental factors such as rural living, farming and exposure to chemicals used in agriculture and increased incidence of PD [6]. A number of environmental stimuli are associated with the disease including herbicides, pesticides, cyanide, carbon monoxide and heavy metals [20,21].

\subsubsection{Pesticides and Herbicides as Risk Factors for PD}

Over the years there has been an increased focus on pesticide exposure and PD. Studies have shown a strong correlation between long term pesticide exposure and increased risk of PD [22]. It has been hypothesized that many of the chemicals used in agriculture may be capable of selectively targeting the dopaminergic neurons, accelerating the development of PD. In order to better understand the role of environmental toxins in PD, many toxin-based models have been developed.

\section{Paraquat Model of PD}

Paraquat (PQ), or 1, 1'-Dimethyl-4, 4'-bipyridinium, is a quaternary nitrogen herbicide commonly used to kill broad leaf weeds. Although banned in the United States and in countries of the European Union, it is still used in many developing countries. Investigations into $\mathrm{PQ}$ began after the revelation of a structural similarity with $\mathrm{MPP}^{+}$(1-methyl-4phenylpyridinium) (Fig. 1), a compound most commonly used to induce PD in animals [4].

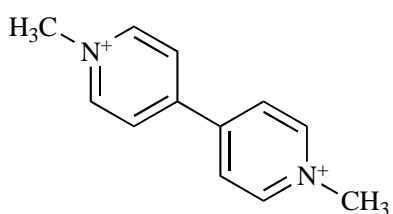

Paraquat

1,1'-dimethyl-4,4'-bipyridinium
$\mathrm{MPP}^{+}$

1-methyl-4-phenylpyridinium

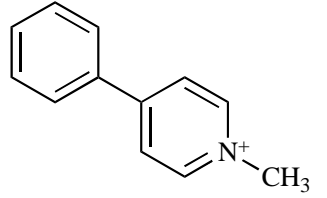

Fig. (1). The structures of Paraquat and $\mathrm{MPP}^{+}$.

Further interest in PQ arose when it was discovered that in Taiwan, where PQ is commonly sprayed on rice fields, people exposed to PQ for at least 20 years had almost a six times higher chance of developing PD [23]. Paraquat is a hydrophilic, charged molecule, and therefore does not diffuse across cell membranes, including the blood brain barrier (BBB) [24]. Studies have shown that PQ enters the central nervous system through neutral amino acid transporters located in the BBB $[25,26]$. Co-administration studies using PQ with competitive inhibitors for the neutral amino acid transporters (e.g., L-valine, L-phenylalanine, L-dopa), revealed a prevention in PQ induced neurotoxicity [26]. Once inside the central nervous system, PQ selectively targets dopaminergic neurons. A study which exposed rat organotypic midbrain slices to $\mathrm{PQ}$, found a dose dependent loss of dopaminergic neurons [27]. The cellular toxicity of PQ is mainly due to its' ability to participate in reactions which produce ROS. In the cell, paraquat is reduced to form a monocation free radical $\left(\mathrm{PQ}^{*+}\right)$ by either NADPH-cytochrome P-450 reductase [28], cy tochrome $\mathrm{C}$ reductase [29], or complex I of the mitochondrial electron transport chain [30]. The monocation free radical form of PQ then reacts with oxygen to form a super-oxide radical $\left(\mathrm{O}_{2}{ }^{*}\right)$. Once the super-oxide radical is formed, it can react through well known mechanisms to create other reactive oxygen species, all of which are harmful to the cell [24]. Recently, Castello et al. [31] revealed the involvement of the mitochondrial respiratory chain complexIII in the production of ROS upon paraquat exposure. McCarthy et al. [32] showed that PQ exposure caused neuronal cell death in vitro by inducing oxidative stress and causing mitochondrial dysfunction.

\section{Rotenone Model of PD}

Rotenone is a naturally occurring compound which Native Americans traditionally used to poison fish [21]. Today, rotenone is used as an insecticide in gardens and to kill nuisance fish in lakes and reservoirs [33,34]. Rotenone is highly lipophilic and as such, easily diffuses across the blood brain barrier. It prevents oxidative phosphorylation through inhibition of complex I of the mitochondrial electron transport chain. Studies have shown highly specific degeneration of the dopaminergic neurons in the substantia nigra in rats subjected to rotenone [33,34]. Additionally, development of physical symptoms of PD such as bradykinesia (slow execution of movement) and rigidity was observed in these animals. Furthermore, many of the dying neurons contained protein aggregates which closely resembled Lewy bodies [34]. It has been generally accepted that rotenone selectively targets dopaminergic neurons through oxidative stress caused by the blocking of complex I in the electron transport chain [21]. In vitro experiments with cells that had the com- 
plex I enzyme replaced with a rotenone insensitive enzyme, showed no mitochondrial impairment, oxidative damage or cell death [35]. Furthermore, using a chronic mid-brain slice culture model, Sherer et al. [35], showed that rotenone selectively killed dopaminergic neurons and that damage could be attenuated with treatment with $\alpha$-tocopherol, an antioxidant. Although it is clear that rotenone exerts its' toxic effects through oxidative stress, the precise mechanism by which oxidative stress arises remains unknown. It has been suggested that one possible source of this oxidative stress may be a site of electron leakage upstream of rotenone's binding site on complex I [36]. When complex I is blocked by rotenone, electrons leaking through this "leak site" could react with oxygen to form reactive oxygen species [34, 36]. Another possible way in which rotenone may cause neurodegeneration is through microglial activation. Since the substantia nigra contains a large amount of microglia cells, the activation of microglia has been investigated as a possible cause of neurodegeneration in PD [37].

\section{Multihit Hypothesis}

Most of the studies identifying environmental toxins targeting the DA neurons have focussed on the use of a single chemical to induce PD. However, humans are exposed to multiple toxins in the environment. The multihit hypothesis proposes that the brain is able to resist the effects of an individual chemical that targets the DA neurons. However, the defense machinery may be compromised when several toxins target different sites in DA system, ultimately leading to neuronal damage and cell death eventually. Of the different models using combinations of toxins to study PD, the PQ and maneb (MB) models have emerged as a multihit model, in which the two toxins act synergistically to induce PD-like pathology. Studies using a combination of MB and PQ have shown greater neuronal damage than either chemical alone [4]. The PQ-MB model has also been used to study the combined effects of exposure to environmental neurotoxins, as well as aging on the risk for PD development [38].

\subsubsection{Metals as Neurotoxic Agents in PD}

Metals, particularly transition metals, have been investigated as a possible cause of PD. Case-control studies have shown that PD can be associated with chronic exposure to metals such as manganese or copper [39]. Furthermore, dual combinations of lead, iron and copper can also be associated with PD [39]. It has been observed that the substantia nigra region of PD patients show elevated levels of some metals; particularly iron, which can participate in reactions such as the Fenton reaction to produce oxidative radicals [40, 41]. Metal induced oxidative stress can target lipids, proteins and even DNA in the cell which in turn can cause cell death through mitochondrial dysfunction, excitotoxicity, and a rise in the cytosolic $\mathrm{Ca}^{2+}$ levels [42].

Copper (II), iron (II), cobalt (III) and manganese (III) have all been shown to interact with $\alpha$-synuclein and promote its aggregation. $\alpha$-synuclein is a small protein $(14 \mathrm{kDa})$ and a major component of Lewy bodies. Since metals can increase aggregation of $\alpha$-synuclein, it is possible that these metals may play a role in the pathogenesis of PD [42].

\subsection{Molecular Mechanisms Contributing to Toxin- Induced Neurodegeneration in PD}

Though the exact mechanism of neurotoxicity is not known, it has been suggested that a cascade of events ultimately leads to the death of DA neurons in the nigro-striatal pathway [43]. Some of these events include oxidative stress, mitochondrial dysfunction, excitotoxicity and neuroinflammation.

\subsubsection{Oxidative Stress and Mitochondrial Dysfunction in $P D$}

Many of the neurotoxins target the mitochondrial electron transport chain and lead to the production of superoxide anion radicals. Superoxide dismutase present in the mitochondrial matrix, acts as an antioxidant and converts most of the superoxide anion radicals to hydrogen peroxide. The Fenton reaction then converts hydrogen peroxide into hydroxyl radicals. All these species are capable of exerting damage to the cell by modifying lipids, proteins and DNA. Oxidative stress-induced neuronal loss has been implicated in the progression of PD [44].

The contribution of oxidative stress in PD nigral cell death has been demonstrated by post-mortem studies in PD patients as well as by toxin-induced PD models [9, 45]. Even under normal conditions, the $\mathrm{SN}$ region is subjected to oxidative stress due to various reasons including the production of ROS during dopamine metabolism, high levels of iron and copper that are essential cofactors for enzymes concerned with the catecholamine metabolism and high levels of oxidized GSH $[9,46]$. Post mortem studies of PD patients have shown higher iron levels in the SN region [47-49]. Increased levels of lipid peroxidation, DNA damage and protein oxidation have been observed in the SN region in PD patients [5056]. A decrease in the levels of reduced GSH by about $50 \%$ in PD substantia nigra has been reported [56-59]. In the brain, GSH is known to play a vital role in detoxification of ROS [44]. The lowered glutathione content appears to be the earliest marker for oxidative stress during the progression of PD [60] prior to the inhibition of complex I of the mitochondrial respiratory chain [44].

There is overwhelming evidence implicating the role of oxidative stress in amplifying damage to the $\mathrm{SN}$ neurons during PD. Oxidative and nitrosative stress, among other factors, may be able to manipulate the aggregation and folding of proteins such as $\alpha$-synuclein, (a prominent component of the Lewy body) into different forms including protofibrils, fibrils, and filaments. An accumulation of misfolded forms of $\alpha$-synuclein contribute to neuronal cell death $[61,62]$. The ubiquitin proteasome system can be directly or indirectly affected by oxidative stress. Direct oxidation of the components of the proteasomal system can affect its function. Amplified production of oxidatively modified proteins can also devastate the ubiquitin proteasomal system leading in a toxic accumulation of damaged proteins in the cell [63]. Additionally, nigral dopaminergic cells are more susceptible to oxidative and proteolytic stress due to the low steady-state levels of proteasome activators observed in the SN of PD patients [64]. It is known that parkin has ubiquitin-3 ligase like activity, and S-nitrosylation of parkin may impair its ability to ubiquitinate proteins $[61,65]$. 
Dopamine metabolism leads to production of hydrogen peroxide which is then converted to the hydroxyl radical that is very toxic [66]. However, has been no direct evidence that links superoxide anion radical production to dopamine metabolism and mitochondrial dysfunction [45]. Interestingly, data has shown that nitric oxide (NO) can cause the oxidative damage in PD by reacting with superoxide to form peroxynitrite $[67,68]$. It has been reported that displacement of iron from ferritin is caused by NO leading to degeneration of the cells [69]. NO inhibits glutathione reductase, thereby affecting GSH levels [70]. NO also causes DNA singlestrand breaks and increases DNA oxidation [50, 54].

It is yet to be determined which one of the two species, ROS or reactive nitrogen species (RNS), is the main culprit in PD. Moreover, since oxidative stress has been linked to other cellular processes such as cell death, inflammation, excitotoxicity and mitochondrial dysfunction, it is not easy to establish whether or not oxidative stress is a product or the prime initiating agent of these events [45, 49].

There has been mounting evidence suggesting the involvement of mitochondrial dysfunction in PD [43] and furthermore, impairment of complex I function in the mitochondrial electron transport chain [71, 72]. Mitochondria are responsible for the generation of ATP in the presence of oxygen and mitochondrial dysfunction leads to decreased ATP production. Many environmental toxins including rotenone and paraquat cause the inhibition of electron transport in the respiratory chain [73]. Studies involving toxin-induced PD in animal models by MPTP as well as rotenone have revealed a loss in the activity of complex-I. Post-mortem studies of PD patients have revealed a loss in about 30-40\% activity of complex-I in the SN region [72]. Reactive species such as NO can reversibly and irreversibly inhibit complexes-I and IV, and although the mechanism of action of NO remains vague, it is hypothesized that it may involve the S-nitrosylation of thiol groups in the complexes [70, 74]. Mitochondria are generators as well as the targets of nitrating species. In vitro and in vivo studies have shown that mitochondrial proteins including MnSOD, aconitase, cytochrome $c$, voltage-dependent anion channel (VDAC), ATPase, and succinyl- CoA oxoacid-CoA transferase are nitrated [239].

It has been shown that elevated oxidative stress leads to mitochondrial dysfunction and a decline in ATP production [49]. In vitro studies in our lab have shown that under oxidative stress, there is a decline in the mitochondrial ATP production [32]. Reduction in ATP levels causes the inhibition of PA700, which is an activator of the 26S proteasome, resulting in decreased ubiquitination [43, 45]. Additionally, mitochondrial dysfunction leads to the failure of ATPdependent magnesium inhibition of N-methyl-d-aspartate (NMDA) receptors and thereby escalating vulnerability to excitotoxicity [43].

\subsubsection{Excitotoxicity in PD}

No direct evidence has been found to implicate excitotoxicity in PD, however, it has been suggested that glutamate may have a toxic effect on the DA neurons in the $\mathrm{SN}$ region because this region receives glutaminergic projections from the subthalamic nucleus [75]. Increased activity of the subthalamic nucleus has been shown in animal models as well as PD patients [76]. MPTP induced animal models of PD have shown altered glutamate activity, while co-injection of MPTP with glutamate antagonists offered protection to the DA neurons from the deleterious effects of glutamate [7779]. It has been suggested that although selective loss of DA neurons occurs in the SN, glutamate is not implicated primarily and excitotoxcity is more unlikely to play a role in a chronic progressive disease such as PD [75].

\subsubsection{Role of Neuroinflammation in PD}

The role of inflammation in neurodegenerative diseases such as PD is not well understood and the events triggering the inflammatory response are unclear. Astrocytes as well as glial cells play an important role in neuroinflammation. In $\mathrm{PD}$, the degeneration of dopaminergic neurons is coupled with immense microglial activity [80]. This increase in activity could be a consequence of neuronal cell death or might be due to the participation of microglia in the cell death process. Most of the evidence has been gained through in vitro and in vivo studies. Both the MPTP and the 6-hydroxydopamine (6OHDA) induced PD models have been shown to induce the activation of astrocytes in the striatum [17,81]. The contribution of altered glial function to the demise of the DA neurons has been observed on co-incubation of these neurons with toxins such as MPTP and 6-OHDA [82]. The detection of elevated levels of pro-inflammatory cytokines and increased oxidative-stress inflicted damage in post mortem samples from PD patients suggests that the role of microglial activation is significant in the degenerative processes occurring in PD [83].

Elevated glial reaction associated with the loss of DA neurons during PD implies that microglial activation may prompt or contribute to the neurodegenerative process in the disease. McGeer et al. [84] have uncovered that the response of glial cells is more robust in the SN than the striatum, albeit damage to DA neurons is more severe in the striatum. Microglia become activated in the brain responding to various insults, proliferate and start expressing noxious molecules such as ROS, RNS, cytokines and pro-inflammatory prostaglandins [85]. Other sources of ROS production include NADPH-oxidase present in the microglia [86] and cyclooxygenase- 2 . This enzyme exerts its toxic effect during catalysis of prostaglandins, causing the oxidation of dopamine to dopamine-quinone [87], which is extremely reactive with GSH and amino acids such as lysine, tyrosine and cysteine, in due course ensuing in cell death [83].

Amplified levels of pro-inflammatory cytokines such as tumor necrosis factor- $\alpha$ and interleukin- $1 \beta$ have been observed in the cerebrospinal fluid as well as striatum of PD patients [88]. These cytokines are potent activators of inducible NO synthase (iNOS) in rodents [83]. Cytokines released from glial cells bind to their specific receptors found on the DA neurons. Upon binding to their corresponding receptors, these cytokines trigger apoptosis by activating caspase- 3 via the extrinsic pathway $[89,90]$. In many cases of PD, a slight raise in the astrocyte counts as well as the immunoreactivity of glial fibrillary acid protein (GFAP) have been detected, but fully reactive astrocytes have been found in only a few cases [91]. Besides, the number of GFAP positive astrocytes inversely correlates to the sum of DA neurons undergoing death [92] and the number of $\alpha$-synuclein positive astrocytes associates to the severity of cell death in PD [93]. Regretta- 
bly, no techniques exist to study the relationship between the DA loss and microglial activation in either PD patients or toxin-induced PD models. Teismann and Schulz [83] have proposed that glial cells play an unfavourable role and activation of microglia plays a key part in PD. However, it is less likely that inflammation is responsible for initiation of the death of the SN neurons.

All the above mentioned events play an important role in the progression of PD. Since a complex inter-relationship exists between them, it is very difficult to pinpoint which event occurs first.

\subsection{Psychological and Lifestyle Correlates of Parkinson's Disease}

Various co-relational studies found an association between social and psychological factors and PD. The present discussion reviews the research on smoking, stress, and depression, among others, as they relate to neurodegeneration in the SN. However, note that there is little evidence as to the specific biochemical mechanisms that mediate these associations.

\subsubsection{Smoking, Alcohol, and Caffeine Consumption}

A negative association between smoking and PD has been shown, with heavy smokers having a risk up to $50 \%$ lower than non-smokers [94]. According to another study, smokeless tobacco use has been inversely associated with PD mortality [238]. Present smokers are better protected than past smokers. Wirdefeldt et al. [95] confirmed the protective effects of smoking and established that they are not fully explained by genetic and familial factors. In his review, Logroscino [96] suggested that smoking is a protective agent for the onset, but not the progression of PD, even when familial and personality factors are controlled for. A systematic study looking at the age when subjects began to smoke may shed further light on this relationship. However, other studies did not confirm this association. Rajput and Birdi [97] identified four requirements that would establish the protective effects of smoking: lower incidence of PD, delayed onset of $\mathrm{PD}$, slower progression of $\mathrm{PD}$, and a dosedependent progression of PD in smokers compared to nonsmokers. Various studies satisfied some, but not all of these requirements. In a study of $237 \mathrm{PD}$ patients and 474 normal individuals, ever-smoking was negatively associated with PD [98]. Haack et al. found that age of onset was also delayed, but failed to identify a dose-dependent relationship [99]. On the other hand, Grandinetti et al. identified a dosedependent relationship but the age of onset did not differ between smokers and non-smokers [100]. Lastly, smoking seems to have some protective effects in males, but not in females [101]. In terms of the mechanism of this effect, it has been proposed that nicotine is an antioxidant and an inhibitor of monoamine oxidase B (MAO-B) [96]. MAO-B is involved in dopamine catabolism and MPTP activation. Postitron-emission tomography scans showed decreased levels of MAO-B in smokers [102]. Therefore, it has been hypothesized that reduced MAO-B activity leads to decelerated dopamine catabolism and poor or no activation of toxic substances.

The relationship between smoking and Parkinsonism may be confounded by other lifestyle factors, such as caf- feine consumption. Caffeine consumption has also been associated with lower risk of PD [101]. Some studies found that coffee drinkers had a 30\% lower risk of developing PD than non-coffee drinkers [96]. MPTP-induced dopaminergic loss was reduced in mice that were initially treated with caffeine. This effect may be mediated by the blockage of adenosine-2 receptors [103]. Alcohol may also provide a protective effect [104], although some studies did not identify an association [105].

\subsubsection{Psychiatric Disorders and Incidence of PD}

When socioeconomic status and geographical region are controlled for, psychiatric disorders (schizophrenic, mood and neurotic/personality disorders) seem to predict PD [106]. The overall risk was higher for women than men and higher for individuals under 50 years of age, a surprising finding because in the general population men over 50 are more commonly affected [107]. Overall, the prevalence of PD in patients with a psychiatric disorder was statistically higher than in the normal population regardless of age [106]. In one study, the maximum rate of PD occurred ten years earlier in the psychiatric disorders group than in the non-hospitalized group. Other studies suggested that $40 \%$ of the individuals with a history of mood and anxiety disorders developed PD [108]. These relationships are likely to be mediated by chronic stress, poor social support, and maladaptive coping strategies [106]. Poor diet and physical inactivity are also signals of an overall lifestyle pattern often associated with low socioeconomic status, psychiatric disturbances, and PD.

\subsubsection{Anxiety and PD}

While some studies suggest that anxiety appears after the onset of PD [109, 110], many indicate that it precedes PD $[111,112]$. In a prospective study, Weisskopf et al. [113] found that phobic anxiety is a risk factor for PD in men. Several case-control studies supported this finding [114, 115]. The relationship remained significant after adjusting for age, smoking, and caffeine consumption. A twofold increase in the risk of PD was observed when anxiolytic medication was used. Controlling for medication did not affect the relationship between PD and anxiety. Shiba et al. [115] also found that anxiety preceded PD by 5 to 20 years, making it unlikely that it was a result of unrecognized symptoms of PD. Weisskopf et al. [113] suggested that anxiety and PD share some biological commonalities, such as dysfunction of the dopaminergic system, reduced striatal dopamine uptake, and reduced levels of dopamine metabolites (homovanillic acid) in the cerebrospinal fluid. Other neurotransmitter systems such as norepinephrine, serotonin, GABA ( $\gamma$-aminobutyric acid) and acetylcholine have also been implicated in anxiety and may affect PD by interacting with dopaminergic neurons $[113,116,117]$. Alternatively, it has yet to be determined whether anxiety is part of a pre-morbid personality trait that predisposes individuals to PD (as discussed below).

\subsubsection{Depression and $P D$}

Numerous studies confirm a positive relationship between depression and PD [118], with some data indicating a prevalence of depression in up to $90 \%$ of PD cases [119]. However, the directionality of this association is controversial. Depression may be a reaction to illness, whereas PD may constitute a risk factor for depression [120], or clinical 
depression and PD-associated depression may be completely different conditions, with different underlying mechanisms [119]. However, there is mounting evidence that depression precedes and is a risk factor for PD. In a retrospective cohort study, Schuurman et al. found a strong positive correlation between depression and subsequent onset of PD. Controlling for age, sex, and socioeconomic status did not affect the result [118]. The relationship may be mediated by low serotonin activity, a risk factor for PD. Low serotonin leads to increased striatal dopamine, a mechanism that can compensate for the loss of dopamine neurons in PD while increasing the risk of depression. Therefore, a biological vulnerability towards depression may interact with environmental and personality factors, resulting in the development of Parkinsonism. This model raises the question of whether depression should be considered as an independent disorder or as an early symptom of PD.

Leentjens [120] suggested that depression does not predispose to PD in particular, but rather to a variety of other disorders, including Alzheimer's disease, cancer, and cardiovascular disease. Future research should establish the directionality and specificity of the relationship between depression and PD in order to avoid confounding factors in the diagnosis and management of PD. Several hypotheses have been proposed, but conclusive findings are limited. Shiba et al. [115] suggested that depression may cause PD directly or indirectly via antidepressant medications, increased glucocorticoid levels, decrease in neutrontrophic factors, or common patterns of gene expression.

\subsubsection{Role of Chronic Strain in PD}

Kuopio et al. [121] suggested that heavy work is associated positively with $\mathrm{PD}$, while living in close proximity to domestic animals, be it in a closed home environment or on a farm, is a protective factor. It may be that some other factor, such as lower chronic stress, mediates this relationship. Similarly, it was found that living in small cities or villages is negatively correlated with PD [6, 122].

Schaie and Lawton postulated [123] that acute or longterm stress can precipitate the onset of illness, leading to downregulation of bodily systems, including the nervous system, the cardiovascular system and the locomotor system. Hartmann et al. [124] found an interesting link between chronic stress and PD. The stress response is mediated in part by the hypothalamic-pituitary-adrenocortical axis (HPA), whose repeated activation may lead to a chronically high level of cortisol and catecholamines. This may result in neuroendocrine imbalances. According to Hartmann et al. [124] basal hypercortisolemia is associated with PD. Compared to normal controls, cortisol levels did not fluctuate and cortisol was released in higher quantities in patients with PD. Also, note that dopaminergic projections extend to the hippocampus, where repeated HPA activation was associated with neuronal loss [107]. Future studies should identify whether such neurodegeneration also occurs in the substantia nigra.

Gale et al. [125] suggested that the stressful conditions in war camps may have detrimental effects on the substantia nigra, which manifest in Parkinsonism due to age-related neuronal loss [125]. Other studies also suggested a twofold increase in PD in former prisoners of war [126].
Exercise is a well-known stress-reliever in humans [107]. Therefore, physical activity may provide some neuroprotective effects with regards to PD. In 6-OHDA treated mice, Howells et al. [127] found that exercise was associated with attenuated symptoms as measured by rotation in response to apomorphine. A distinct group was subjected to stressful circumstances consisting of unpredictable wheel immobilization, food deprivation, and circadian cycle alteration. Upon apomorphine administration, the results from this group were not significant from a non-runners group. The results indicated that stress cancelled the protective effects of exercise. The protective effects of exercise may involve improved cerebrovascular circulation and production of neurotransmitters and neurotrophic chemicals [128]. In addition, exercise may affect dopamine metabolism directly: some studies reported a $30 \%$ increase in neostriatal dopamine in mice forced to exercise [235].

\subsubsection{Traumatic Brain Injury and PD Incidence}

A relationship between PD and brain injury has been found in multiple studies, although epidemiological investigations did not consistently confirm it [129-131]. In addition, the sporadic associations that have been observed could be confounded or mediated by other variables. For instance, individuals who are prone to head injury may have a genetic predisposition to engage in risk-taking behaviours or to seek particular occupations (such as farming). In a study on monozygotic and dizygotic twins, however, Goldman et al. [132] found that loss of consciousness and head injury with amnesia were correlated to an increased risk of PD later in life. The relationship was stronger for monozygotic twins and increased with multiple injuries and with severity of injury. With genetic and environmental factors controlled for, this study suggests a direct causal relationship between head insult and PD.

A variety of psychological and lifestyle factors have been associated with PD. However, further research should address the potential variables that may mediate this relationship.

\subsection{Advances in Therapeutic Approaches for PD}

PD is a progressive neurodegenerative disease and the rates of progression vary amongst different patients. Since several factors are involved in the progression of PD, various neuroprotective strategies have been developed. However, most of these agents have been identified in animal models of PD, making it difficult to prefer different drugs and assess them in humans [43]. Much of the therapy for PD is symptomatic and is short of important disease-modifying effects. The most effective therapy is levodopa which is often given in combination with other drugs. Surgery is another option which is held in reserve for complex cases of PD in which motor complications or medical intolerance has led to an intolerable decline in the quality of life [61].

Scientists have focussed on compounds that can slow or impede the progression of PD. Many neuroprotective agents such as monoamine oxidase inhibitors, antiexcitatory drugs, trophic factors such as glial cell derived neurotrophic factor (GDNF), dopamine agonisits and antiapoptotic drugs have been studied for their potential as possible therapeutics. The properties of bioenergetic compounds such as creatine, ribo- 
flavin, nicotinamide and Coenzyme $\mathrm{Q}_{10}\left(\mathrm{CoQ}_{10}\right)$ as budding candidates for neuroprotection have been assessed [43, 133].

A lot of focus has been on $\mathrm{CoQ}_{10}$, which is a hydrophobic, naturally occurring compound which transfers electrons between the different complexes of the mitochondrial electron transport chain and is a very pivotal antioxidant in the mitochondria where it readily scavenges free radicals [133]. Neuroprotective effects of $\mathrm{CoQ}_{10}$ in the central nervous system in several in vivo studies have been demonstrated by the prevention of reduction in the GSH and ATP levels, as well as protection during experimental ischemia [133]. An openlabel phase trial of $\mathrm{CoQ}_{10}$ in $\mathrm{PD}$ patients found good $\mathrm{CoQ}_{10}$ absorption and tolerability [134]. Although very encouraging results were obtained from this study, Beal and Shults [134] have cautioned that it would be early for PD patients to take high dosage of $\mathrm{CoQ}_{10}$ until a bigger trial has been completed.

A major drawback in working with $\mathrm{CoQ}_{10}$, is that it is very lipophilic and studying its protective properties in cell culture is difficult due to its hydrophobic nature; however through a patented protocol (US patent \#6 045 826), a watersoluble formulation of $\mathrm{CoQ}_{10}\left(\mathrm{WS}-\mathrm{CoQ}_{10}\right)$ was developed by Sikorska and Borowy-Borowski of the National Research Council of Canada. McCarthy et al. [32] have shown that PQ induced neuronal cell death could be prevented by pretreating the neurons with a WS-CoQ ${ }_{10}$. Protection of differentiated neuronal cell against cell death induced by glutamate excitotoxicity was also reported by WS-CoQ $\mathrm{W}_{10}$ [135]. Recently, WS-CoQ 10 was shown to inhibit Bax activity and thus prevent Bax-induced destabilization of mitochondria in mammalian cells [136]. Studies in our lab have shown that $\mathrm{WSCOQ}_{10}$ offers protection against PQ induced neurotoxicity in vivo.

Creatine has shown to offer neuroprotection in several toxin-induced PD models and is currently being assessed in early stage trials in PD [133]. The effects of nicotine on neuroprotection have also been investigated. There is evidence that nicotine and subtype selective $\mathrm{nAChR}$ ligands can offer neuroprotection in cell culture systems and in animal models of neurodegenerative diseases such as PD and AD. [236]. It has been revealed that chronic oral nicotine offers partial protection against MPTP-induced striatal damage in monkeys. Furthermore, enhanced synaptic plasticity by lowering threshold for long time depression was observed by nicotine treatment alone [237]. Detailed investigation of the neuroprotective abilities of these compounds alone, or in combinations will provide better therapeutic interventions in PD.

\section{ALZHEIMER'S DISEASE (AD)}

\subsection{Oxidative Stress in AD}

Alzheimer's disease affects several million people worldwide, and as such, it is the most common form of dementias. Both incidence and prevalence of AD increase with aging so this disease is gaining social and economic relevance, mainly in the developed countries where the life span is continuously increasing [137]. Alzheimer's disease is marked by neuronal and synaptic loss in the cerebral cortex and hippocampus, as well as formation of senile plaques and neurofibrillary tangles. Most cases of the disease are sporadic, whereas the rare familial form of $\mathrm{AD}$ is an autosomal dominant disease and is associated with specific mutations in the genes encoding for amyloid precursor protein (APP) and presenilin-1 mapped on chromosome 14, and presenilin-2 mapped on chromosome 1 [138]. Susceptible neurons are subjected to both oxidative and mitotic injuries [139]. There is evidence that early neuronal and pathological changes associated with $\mathrm{AD}$ show oxidative damage, indicating that oxidative stress is a very important contributor to the disease. Markers of oxidative damage are present in the susceptible neurons even without evidence of neurofibrillary pathology [140]. It seems that free radicals produced due to oxidative stress, as well as oxidative modifications of proteins, lipids and nucleic acids are pathologically essential for the onset of AD [141].

Oxidative modifications of proteins are indicated by high concentrations of carbonyl groups [142], and increased nitration of tyrosine residues [143]. Oxidative modifications can also lead to cross linking of proteins which might slow down or stop their intracellular and extracellular removal even when targeted with ubiquitin [144]. Lipid peroxidation is indicated by high concentrations of isoprostane, 4-hydroxy2-nonenal, malondialdehyde, and thiobarbituric acid reactive substances, as well as the altered phospholipid composition [145-149]. Furthermore, DNA and RNA oxidation results in increased concentrations of 8-hydroxyl-2-deoxyguanosine (8-OHdG) and 8-hydroxyguanosine (8-OHG) [150]. Also, high DNA fragmentation, nicking and DNA breaks are observable in AD patients indicating the deficient DNA repair mechanisms [151, 152]. Modification to sugars is indicated by increased glycoxidation and glycation [153]. However, affected neuronal cells still have antioxidant defense system in the form of upregulated antioxidant enzymes such as heme oxygenase I, catalase, glutathione peroxidase, glutathione reductase, $\mathrm{Cu}-\mathrm{Zn}$ superoxide dismutase, peroxiredoxins, as well as some heat shock proteins [154].

Oxidative stress induces changes in gene expression and enzyme activities which are mediated through the communication of various signalling pathways, such as stress activated protein kinase (SAPK) pathways, which propagate stress signals from the membrane to the nucleus. SAPKs and their downstream effectors are the ones involved in the ambiguous response to the oxidative stress depending on cellular and environmental conditions: they will provoke a stress response that either leads to apoptosis or to defensive protective adaptations, [155]. The entire JNK (C-Jun N-terminal kinase)-SAPK pathway is affected in AD: JNK1 is related to Hirano bodies in AD, while JNK2 and JNK3 are related to neurofibrillary pathology. JNK-SAPK is activated in AD and redistributed from nuclei to the cytoplasm as the disease progresses. Nuclear localization of active JNK-SAPK is detected in the susceptible neurons in the beginning stages of $\mathrm{AD}$, while phospho-JNK-SAPK is only localized in the association with neurofibrilary tangle formation in advanced AD [156]. The nuclear localization of active JNK-SAPK suggests that oxidative signalling possibly affects the gene expression. This is supported by the fact that activation of JNK-SAPK pathway can modulate the induction of some antioxidant enzymes that are induced in AD such as heme oxygenase- 1 and superoxide dismutase-1 [157].

\subsection{Causes of Oxidative Stress in AD}

The sources of ROS induced damage include abnormal mitochondria, redox transition metals, proteolysis dysfunction, activated microglia etc. [158]. Many studies implicate 
metabolic defects in AD such as reduced rate of brain metabolism, and these abnormalities precede brain atrophy and functional impairment [159]. Also, increased oxidative utilization in $\mathrm{AD}$ patients comparing to glucose utilization has been documented [160].

\subsubsection{Role of Amyloid $\beta(A \beta)$ in Oxidative Stress}

It was initially thought that lesions were the source of ROS in AD. However, it appears that oxidative damage already present in $\mathrm{AD}$ recruits defence mechanisms such as $\mathrm{A} \beta$ deposition and hyperphosphorylation of $\tau$ protein in attempt to restore the redox balance and avoid neuronal death initiated by oxidative stress [161]. However, as the disease progresses, both $\mathrm{A} \beta$ and hyperphosphorylated $\tau$, through gainof-function transformation, shift their activities from antioxidant to prooxidant. This ultimately leads to increased ROS production and compromised defence mechanisms.

Even though it is present in healthy neurons as well as $\mathrm{AD}$ affected ones, $\mathrm{A} \beta$ is considered a dangerous by-product of A $\beta P P$ processing by $\beta$ and $\gamma$-secretases [158]. It was recently reported that $\mathrm{A} \beta$ gets secreted from healthy neurons in response to activity and that it down-regulates excitatory synaptic transmission [162]. Furthermore, $A \beta$ has strong chelating properties for zinc, iron and copper, which suggests that one function of $A \beta$ is to sequester these metals [163]. Theoretically, this sequestering of redox active metals can serve to inhibit metal-catalyzed oxidation of biomolecules. However, the role of $A \beta$ can be considered to be both antioxidant and prooxidant since methionine at residue 35 can both scavenge free radicals [164] and reduce metals to their highly active low-valence form [165]. Therefore, the overall activity of $A \beta$ with respect to oxidation is a combination of metal chelation, metal reduction, and free radical scavenging, which results in either prooxidative or antioxidative activity. In order for $A \beta$ to induce oxidation three conditions have to be satisfied: presence of methionine 35, presence of transition metals, and fibrillation [158]. Fibrillation will only occur if $A \beta$ is aged and present in large (micromolar) quantities [166]. Presence of redox metals is also required for A $\beta$ aggregation and its pro-oxidant activity [163]. Methionine 35 is necessary for pro-oxidant activity of $A \beta$; it has been demonstrated that its substitution greatly diminishes or even aborts the pro-oxidant activity of $A \beta$. In its role as pro-oxidant, $A \beta$ induces peroxidation of membrane lipids [167] and lipoproteins [168], generates hydrogen peroxide [169] and 4-hydroxynonenal (4-HNE) in neurons [170], inactivates transport enzymes [171] and damages DNA [172].

\subsubsection{Role of Mitochondrial Dysfunction and Oxidative Stress in $A D$}

Since metabolic impairments (such as hypoxia, hypoglycaemia etc.) are sufficient to induce mental and neurological impairments similar to those of $\mathrm{AD}$, it is evident that mitochondrial dysfunction may play a role in the onset of $\mathrm{AD}$ [173]. Characteristics of AD include damaged mitochondria and increased oxidative stress, which is consistent with the finding that damaged mitochondria produce more ROS and less ATP compared to their normal counterparts [174]. The function of mitochondria is dependent on their intact structure. It has been reported that mitochondria in AD are deficient in some key enzymes involved in oxidative metabolism such as $\alpha$-ketoglutarate dehydrogenase complex, pyruvate dehydrogenase complex (both enzymes of Krebs cycle) and cytochrome oxidase (responsible for reducing molecular oxygen in the electron transport chain) [175]. Different stages of mitochondrial abnormality are present in almost all AD neurons. Quantitative measurements of the percentage of normal, partially damaged and completely damaged mitochondria show that AD neurons have significantly higher proportion of damaged mitochondria and significantly lower percentage of normal mitochondria compared to their normal counterparts [158]. Factors that contribute to mitochondrial dysfunction in AD are following: low vascular blood flow in the brain [176], increased sporadic mutations in mitochondrial DNA which negatively affect mitochondrial stability [177], $A \beta$ and $A \beta P P$ processing machinery located in mitochondria where A $\beta P P$ is present in mitochondrial import channel thus potentially affecting mitochondrial transport [178], and increased homocysteine (hyperhomocysteinemia). Increased homocysteine observed in $\mathrm{AD}$ inhibits several genes that encode mitochondrial proteins ultimately promoting ROS production [179].

\subsubsection{Metal Toxicity in $A D$}

Most types of oxidative stress damage in AD are linked to metal-catalyzed hydroxyl radical formation, so loss of iron and copper homeostasis in the brain is accompanied by serious neurological consequences. Iron is involved in hydroxyl radical formation through the Fenton reaction. It has been recorded that iron accumulates in the brain where it participates in the formation of an increased oxidative stress [180]. Over-accumulation of iron in AD is found in cerebral cortex, hippocampus, and basal nucleus of Meynert, which coincides with the location of neurofibrillary tangles, senile plaques and lesions in AD brain [181]. RNA bound iron plays a role in RNA oxidation in the neurons of AD [182]. rRNA is present in large amounts in neurons, and it is considered to have the largest number of iron binding sites among all cytoplasmic RNA species. Oxidation of rRNA by iron dependent Fenton reaction leads to the formation of 8OHG Also, ribosomes obtained from AD hippocampus contain significantly higher levels of RNAse sensitive iron comparing to the controls, as well as 8-OHG detected by immunoprecipitation which is present exclusively in AD brain and not in controls. rRNA serves as a binding site for redox active iron and serves as redox center in the cytoplasm of AD neurons. Oxidized ribosomes in turn show significant reduction in protein synthesis. These ribosomal changes that are due to iron mediated oxidation show well in advance to other morphological changes in AD neurons indicating neurodegeneration [182].

Copper is required by many oxidation-reduction enzymes. It is found in $\mathrm{Cu}-\mathrm{Zn}$ superoxide dismutase, and in catalytic site of cytochrome oxidase within electron transport chain. Copper entry into the brain is mainly mediated by ceruloplasmin, a copper binding protein responsible for protecting the neurons against oxidative stress; any abnormalities in ceruloplasmin may lead to oxidative damage in the brain [158]. Ceruloplasmin is also involved in the regulation of the redox state of iron by converting ROS catalytic Fe(II) to $\mathrm{Fe}(\mathrm{III})$ which is less reactive. Ceruloplasmin concentration is increased in the cerebrospinal fluid and brain tissue of $\mathrm{AD}$, while its concentration in the neurons remains unchanged [183]. Increased ceruloplasmin concentrations in the cere- 
brospinal fluid may be an attempt to respond to increased oxidative stress in AD, while failure to get up-regulated in the neurons may explain the metal catalyzed oxidative damage in the AD neurons [184]. Furthermore, copper can play a role in ROS generation through its binding to A $\beta P P$. A $\beta P P$ is able to reduce $\mathrm{Cu}$ (II) to $\mathrm{Cu}(\mathrm{I})$ through formation of $\mathrm{A} \beta \mathrm{PP}$ $\mathrm{Cu}$ (II)-hydroxyl radical intermediate, which ultimately enhances production of hydroxyl radical. Copper, like iron, is highly concentrated in $\mathrm{A} \beta$ plaques [158].

\subsubsection{Glycation and Glycoxidation Induced Oxidative Stress in $A D$}

Advanced glycation end products (AGEs) are generated by non-enzymatic reaction of sugar ketone or aldehyde group with free amino groups of a protein or free amino acids, especially arginine and lysine [158]. AGEs are formed through a complex cascade of dehydration, oxidation, fragmentation and cyclization reactions with Amadori product as an intermediate in the process [185]. Amadori products can be converted to protein-dicarbonyl compounds in the presence of molecular oxygen and transition metals via protein enendiol, ultimately generating the superoxide radical. Also, monosaccharides in the equilibrium with their enendiol can undergo auto-oxidation in the presence of transition metals to form enendiol radical. The enendiol radical can reduce molecular oxygen to form the superoxide radical. Advanced glycation end products result in formation of oxygen-derived free radicals, and as such are important source of oxidative stress in AD. Furthermore, accumulation of AGEs is present in the aging brain [186]. In vitro studies showed that AGE modified $A \beta$ promotes rapid aggregation which is a feature associated with AD [187]. AGEs are also detected in neurofibrillary tangles. It is hypothesized that glycation of $\tau$ protein leads to stabilization of helical filaments and $\tau$ aggregation, ultimately leading to neurofibrillary tangles [188]. The role of AGEs in AD is also demonstrated by their neurotoxicity and ability to increase levels of $\mathrm{A} \beta$ [189]. Furthermore, AGEs and $A \beta$ activate specific receptors such as class A scavenger receptor [190] and receptor for advanced glycation end products (RAGE) [191] leading to an increase in intracellular ROS levels [158].

\subsubsection{Protein Homeostasis and Oxidative Stress in AD}

Degradation of oxidatively modified non-functional proteins is an important part of the cellular antioxidant defence system. The proteasome is a large intracellular protease responsible for degradation of misfolded, oxidized or truncated proteins utilizing the process of ubiquitination of the proteins targeted for degradation [158]. Components of the proteasomal complex are affected by oxidative stress, with $26 \mathrm{~S}$ proteasome being the most vulnerable [192]. It has been reported that proteasomal activity declines with age [193]. The fact that $\tau$ protein $(\mathrm{PHF}-\tau)$ is heavily ubiquitinated indicates the proteasome involvement in the pathogenesis of $\mathrm{AD}$ [158]. Further studies found decreased activity of proteasome in AD [194], and indeed, inhibition of proteasomal activity has been found to lead to neuronal death and neuropathology similar to that of AD. Moreover, chronic proteasome inhibition, together with increased protein insolubility, induces increased levels of protein oxidation and potentially leads to increased oxidative stress that is observed in AD [64]. Cellular oxidative stress levels can also be increased by lysosomal dysfunction. Lysosomal degradation of iron- containing proteins found in various organelles results in intra-lysosomal formation of redox active iron. This can lead to increased lysosomal oxidative stress, rupturing of the lysosomal membrane and release of intra-lysosomal contents. This leads to an increase in cellular oxidative stress and mitochondrial damage, which in turn leads to an increase in ROS production by mitochondria [158]. Moreover, lysosomes gradually accumulate non-degradable polymeric lipofuscin due to continuous oxidative stress, and even though lysosomes still receive newly synthesized lysosomal enzymes, lipofuscin remains non-degradable. Lipofuscin accumulation may diminish delivery of lysosomal enzymes to functional autophagosomes, which diminishes lysosomal degradation of mitochondria and mitochondrial recycling thus leading to an increase in cellular oxidative stress. This theory is supported by findings indicating that an increase in mitochondrial DNA in the cytoplasm of neurons and in vacuoles containing lipofuscin is associated with increased oxidative damage in AD [158].

\subsubsection{Role of Neuroinflammation in Oxidative Stress in $A D$}

Inflammation in the AD brain can be caused by injured neurons, amyloid plaques and neurofibrillary tangles. This is supported by the finding that both microglia and astrocytes are attracted to the sites of $\mathrm{A} \beta$ deposition. Attracted microglia are activated which is seen through altered morphology and increased expression of major histacompatibility complex class II. Astrocytes express a wide range of inflammatory mediators such as cyclooxygenase, compliment system protein and cytokines [195]. Both activated microglia and astrocytes are capable of producing large amounts of RNS and ROS which are used to attack the targets in inflammation. In addition, $\mathrm{A} \beta$ can directly activate NADPH oxidase of microglia, which leads to an increase in production of hydrogen peroxide and superoxide radicals [196]. Furthermore, activated microglia and astrocytes can produce large amounts of NO upon induction of iNOS gene. NO can react with superoxide to form peroxynitrite, leaving nitrotyrosine as a marker of oxidative stress. Excess NO in AD is confirmed by increased amounts of nitrotyrosine modified proteins [181]. In addition, myeloperoxidase (MPO) in AD microglia represents free radical generating mechanism. MPO catalyzes a reaction between hydrogen peroxide and chloride to form hypochlorous acid which can further react with other molecules to generate other kinds of ROS. MPO can also catalyze formation of nitrotyrosine modified proteins and glycation end product modifications which are observed in AD. Also, there is evidence that MPO is present in activated microglia around amyloid plaques in $\mathrm{AD}$ brain, and that $\mathrm{A} \beta$ aggregates increase MPO mRNA expression in microglia in vitro, both of which support the indicated role of MPO and microglia in the pathogenesis of AD [197].

\subsection{Oxidative Damage in the Peripheral Tissues of AD}

Increased oxidative damage is a common feature in neurons and peripheral cells in both sporadic and familial AD [198]. One of the ways to detect oxidative damage to the biomolecules in the peripheral cells is to measure the end products of lipid peroxidation and protein oxidation [199]. It has been demonstrated that increased DNA damage due to oxidized purines and pyrimidines is present in peripheral 
cells of AD. Patients with mild cognitive impairment (MCI), which is considered to be a possible symptom of early stage of $\mathrm{AD}$, have higher level of oxidative DNA damage than healthy individuals [199]. It has been reported that AD lymphocytes have higher levels of 8-OHdG than controls, measured by HPLC, suggesting that oxidative stress in AD is detectable in peripheral cells as well [200]. Fibroblasts of patients with familial or sporadic AD show an increase in lipoperoxidation products: malondialdehyde and 4-HNE [198]. Naderi et al. [201] demonstrated that ROS levels in AD fibroblasts are markedly higher than in age-matched normal human fibroblasts (NHFs), which gives them typical senescence morphology and resistance to external oxidative stress. It has also been demonstrated that peripheral levels of both enzymatic and non-enzymatic antioxidants are depleted in $\mathrm{AD}$ and MCI patients [202]. Furthermore, lymphoblasts carrying either presenilin-1 or APP mutation show significantly lower GSH content compared to their age matched controls. This finding agrees with the trends of GSH levels in the central nervous system, and as such, it strengthens the importance of oxidative stress in the pathogenesis of AD [138].

\subsection{Neuroprotective Strategies for AD}

\subsubsection{Iron Chelators}

As iron has been implicated in pathogenesis of AD (see oxidative stress section), see the role of iron chelators in the treatment of the disease needs to be investigated. Iron chelators are compounds that bind iron, which consequently renders it inactive and unable to participate in chemical reactions such as those related to the onset of AD [203]. The role of desferrioxamine (DFO), an iron chelator used to treat the conditions of iron overload, in cancer and neurodegenerative disorders, has been recently suggested [204]. CrapperMcLachlan et al. used DFO in a 2-year single blind study where DFO was injected intramuscularly [205]. This treatment slowed down dementia progression associated with AD. The limitation of DFO is its large size and hydrophilic nature which slows down gastro-intestinal absorption and its penetration through the blood-brain barrier [206]. Furthermore, chelation with EDTA has been shown to induce clinical improvement in patients with AD [207]. Also, chronic administration of the chelating agent clioquinol to transgenic mice bearing APP mutation (Tg 2576), led to a decrease in $\mathrm{A} \beta$ build-up in the brain, and slowing down of cognitive decline [208]. Another study showed that lipophilic metal chelator DP-109 when applied to female Tg 2576 mice, resulted in the marked decrease of amyloid plaques [209]. Moreover, House et al. [210] demonstrated in their in vitro studies that both DFO and clioquinol prevent formation of $\beta$ pleated sheets in $A \beta$, and $A \beta$ aggregation, as well as their ability to dissolve previously formed synthetic and ADbrain-derived $A \beta$ aggregates. The identification of an ironresponsive-element loop in 5'UTR of APP led to the discovery of some new chelating drugs that target 5'UTR such as DFO(Fe (III) chelator), tetrathiomolibdate ( $\mathrm{Cu}$ (II) chelator) and dimercaptopropanol $(\mathrm{Pb}$ (II) and $\mathrm{Hg}$ (II) chelator). These drugs suppress APP expression and lower A $\beta$ secretion [211].

\subsubsection{Antioxidants and Antioxidant Drugs}

Antioxidant defence compounds are based on their ability to inhibit free radical formation, scavenge generated free radicals, enzymatically detoxify the accumulated free radicals, and initiate the gene transcription responsible for long term support and induction of cellular self-defence. There are three types of antioxidants, direct antioxidants chemically interfere with the formed free radicals; indirect antioxidants prevent the formation of free radicals; and metabolic antioxidants limit the extent of damage to the cell by reducing the metabolic burden of increased level of ROS. A major group of direct antioxidants are chain braking antioxidants such as monophenolic compounds (e.g. tocopherol (vitamin E), 17ß-estradiol (estrogen), 5-hydroxytryptamine (serotonin), as well as derivatives of tyrosine and polyphenolic compounds e.g. flavonoids, stilbenes, and hydroquinones [212]. The hydroxyl group of vitamin E may donate an electron to inactivate the highly reactive single electron of free radicals. In AD specifically, vitamin E prevents the accumulation of ROS induced by $A \beta$, which reduces toxicity of $A \beta$ in $\mathrm{AD}$ brains [213]. Also, vitamin $\mathrm{E}$ prevents the oxidation of non-saturated carbohydrate side chains of membrane lipids, thus blocking lipid oxidation [214].

Estrogen and vitamin E share the phenolic radical scavenging structure. It is important to point out that the ROS scavenging ability of estrogens is based solely on their structure, and not on their interaction with estrogen receptors [215]. 17 $\beta$-Estradiol is capable of preventing neuronal cell death caused by $\mathrm{A} \beta$, glutamate, hydrogen peroxide, haloperidol, iron (II) sulphate, and ischemic damage [216-218]. Furthermore, compounds such as serotonin, flavonoid, quercetin, and trimethylphenol prevent lipid peroxidation and protect cells against oxidative stress in vitro [219, 220]. Vitamin $\mathrm{E}$ has been used most often as an antioxidant treatment for $\mathrm{AD}$ ever since it was first used in vitro study as a potent protective agent of neuronal cells against $\mathrm{AB}$. It has been reported that vitamin $\mathrm{E}$ slows down cognitive function impairment both in $\mathrm{AD}$ and mild cognitive impairment cases $[214,221]$. Also, idebenone which is structurally similar to ubiquinone (metabolic antioxidant), has been reported to slow down the disease progression when introduced in a dose dependent manner [222, 223].

\subsubsection{Nicotine as a Potential Drug}

Numerous studies suggest that deficits associated with impairments of nicotinic acetyl choline receptors in neurodegenerative disorders can be diminished by treatment with nicotine or other agonists of the receptors. Nicotine and other similar compounds can act through both receptor mediated and non-receptor mediated mechanisms [224]. Nicotine treatment has been shown to be effective in attenuating the decline in some cognitive deficits associated with AD [225]. The molecular mechanisms involved are still not fully understood even though there have been several theories proposed. It has been reported that $\mathrm{A} \beta$ (1-42) binds to $\alpha 7$ nicotinic acetylcholine receptor, which then inhibits $\alpha 7$ receptor dependant calcium influx and ultimately acetylcholine release [226], which could be a possible explanation for cognitive decline in $\mathrm{AD}$. $\mathrm{A} \beta$ peptide and $\alpha 7$ receptor can be immunoprecipitated together suggesting their close interaction, which is confirmed by receptor binding experiments: human neuroblastoma cells with $\alpha 7$ receptor are killed by $A \beta$ peptide, while nicotine has been shown to inhibit their death [227]. According to this, blocking an association between $\alpha 7$ receptor and $\mathrm{A} \beta$ peptide may be a strategy for treating $\mathrm{AD}$. 
Nicotine receptor stimulation can diminish $A \beta$ toxicity [224]; however, some studies show that nicotine directly interacts with $A \beta$. It has been shown that nicotine binds to a small-sized soluble $\beta$-sheet aggregate structure of monomeric $A \beta$ and prevents $A \beta$ senile plaque formation [228]. Alternatively, it has also been reported that the effect of nicotine on reducing $\beta$-amyloidosis is partly mediated by regulating metal homeostasis. Nicotine treatment decreases the intracellular copper concentration and attenuates $A \beta$ mediated neurotoxicity, without activating nicotinic acetylcholine-receptors [229].

\subsubsection{Vaccination Against $A \beta$}

Vaccination of mice with synthetic pre-aggregated $A \beta$ reduced the progression and extent of $\mathrm{AD}$ pathology as reported by Schenk et al. [230]. These findings have paved the way for research in immunization against $\mathrm{AD}$ in humans. Bard et al. [231] presented a method in which antibodies against $A \beta$ are peripherally injected, and then transported to the CNS where they bind $A \beta$ fibrils and target them for degradation by microglia via $\mathrm{Fc}$ receptor ligation. Ex vivo studies following the antibody injection found internalized $A \beta$ in microglia which supports the above hypothesis. Further support for the microglia hypothesis comes from the fact that antibodies of IgG2a isotype are found to be the most effective antibodies (both ex vivo and in vivo studies), considering that $\mathrm{IgG2a}$ isotype antibodies show high affinity for Fc receptors on microglia [232]. Furthermore, microglial activation has been found to accompany plaque clearance in vivo by both active and passive immunization techniques [233, 234].

\section{CONCLUDING REMARKS}

Although tremendous progress has been made in the area of neurodegenerative diseases, the exact mechanisms of these diseases are still not fully understood. One thing is clear that neurons in increased aging populations are vulnerable to oxidative and inflammatory toxicity. Once we understand various factors involved in causing these devastating neurodegenerative diseases like $\mathrm{AD}$ and $\mathrm{PD}$, it would be possible to develop preventative and curative therapeutics. Some of the new advances in neutraceutical research are promising. It is well known that by the time AD or PD are diagnosed, the patients have already lost a good percentage of neurons. The progressive loss of neurons over time leads to further complications. Although, the new research on regenerative therapy or stem cell transplantation could be promising to replace the lost neurons in future, we do not have any evidence of such therapy at present. However, any therapeutic intervention after the diagnosis that can prevent further loss of neurons in the patients could be very useful to maintain a reasonably comfortable life style for many patients. Quenching the toxicity, inhibiting neuronal cell death by blocking pro-apoptotic proteins, stabilizing mitochondrial functions could be realistic targets for researchers to achieve in near future. Furthermore, preventive measures such as decreased exposure to toxic compounds, improved diet, active and stress-free behavioural changes, better work place culture, conducive and pleasant emotional environment and life style could lead to healthy aging and better life during the last chapter of our lives.

\section{ACKNOWLEDGEMENTS}

The authors would like to thank Canadian Institute for Health Research, Heart and Stroke Foundation of Ontario Canada and Toldo Foundation of Windsor for the funding of our research projects.

\section{REFERENCES}

[1] Schober A. Classic toxin-induced animal models of Parkinson's disease: 6-OHDA and MPTP. Cell Tissue Res 2004; 318(1): 215224.

[2] Lang AE, Lozano AM. Parkinson's disease. Second of two parts. N Engl J Med 1998; 339(16): 1130-43.

[3] Giasson BI. Mitochondrial injury: a hot spot for parkinsonism and Parkinson's disease? Sci Aging Knowledge Environ 2004; 48 : pe42.

[4] Cory-Slechta DA, Thiruchelvam M, Barlow BK, Richfield EK. Developmental pesticide models of the Parkinson disease phenotype. Environ Health Perspect 2005; 113(9): 1263-1270.

[5] Tanner CM, Ottman R, Goldman SM, Ellenberg J, Chan P, Mayeux R, Langston JW. Parkinson's disease in twins: an etiologic study. JAMA 1999; 281(4): 341-346.

[6] Tanner CM, Chen B, Wang W, et al. Environmental factors and Parkinson's disease: a case-control study in China. Neurology 1989; 39(5): 660-664.

[7] Ritz B, Yu F. Parkinson's disease mortality and pesticide exposure in California 1984-1994. Int J Epidemiol 2000; 29(2): 323-329.

[8] Braak H, Del Tredici K, Rüb U, et al. Staging of brain pathology related to sporadic Parkinson's disease. Neurobiol Aging 2003; 24(2): 197-211.

[9] Dickson DW. Linking selective vulnerability to cell death mechanisms in Parkinson's disease. Am J Path 2007; 170(1): 16-19.

[10] Olney JW, Zorumski CF, Stewart GR, Price MT, Wang GJ, Labruyere J. Excitotoxicity of L-dopa and 6-OH-dopa: implications for Parkinson's and Huntington's diseases. Exp Neurol 1990; 108(3): 269-72.

[11] Langston JW, Ballard P, Irwin I. Chronic parkinsonism in humans due to a product of meperidine-analog synthesis. Science 1983; 219(4587): 979-980.

[12] Di Monte DA. The environment and Parkinson's disease: is the nigrostriatal system preferentially targeted by neurotoxins? Lancet Neurol 2003; 2(9): 531-38.

[13] Przedborski S, Vila M. The 1-methyl-4-phenyl-1,2,3,6-tetrahydropyridine mouse model: a tool to explore the pathogenesis of Parkinson's disease. Ann N Y Acad Sci 2003; 991: 189-198.

[14] Javitch JA, D'Amato RJ, Strittmatter SM, Snyder SH. Parkinsonism-inducing neurotoxin, $N$-methyl-4-phenyl-1,2,3,6-tetrahydropyridine: uptake of the metabolite $N$-methyl-4- phenylpyridine by dopamine neurons explains selective toxicity. Proc Natl Acad Sci USA $1985 ;$ 82(7): 2173-77.

[15] Daniels AJ, Reinhard JF Jr. Energy-driven uptake of the neurotoxin 1-methyl-4-phenylpyridinium into chromaffin granules via the catecholamine transporter. J Biol Chem 1988; 263(11): 5034-36.

[16] Nicklas WJ, Vyas I, Heikkila RE. Inhibition of NADH-linked oxidation in brain mitochondria by 1-methyl-4-phenyl-pyridine, a metabolite of the neurotoxin 1-methyl-4-phenyl-1,2,5,6-tetrahydropyridine. Life Sci 1985; 36(26): 2503-08.

[17] Przedborski S. Neuroinflammation and Parkinson's disease. Handbook of Clinical Neurology, 2007; Vol. 83 (3rd series) Parkinson's disease and related disorders, Part I, chapter 26: 535-551.

[18] Sedelis M, Schwarting RK, Huston JP. Behavioral phenotyping of the MPTP mouse model of Parkinson's disease. Behav Brain Res 2001; 125(1-2): 109-25.

[19] Terzioglu M, Galter D. Parkinson's disease: genetic versus toxininduced rodent models. FEBS J 2008; 275(7): 1384-91.

[20] Tanner CM, Langston JW. Do environmental toxins cause Parkinson's disease? A critical review. Neurology 1990; 40(10 Suppl 3): suppl 17-30; discussion 30-1.

[21] Uversky VN. Neurotoxicant-induced animal models of Parkinson's disease: understanding the role of rotenone, maneb and paraquat in neurodegeneration. Cell Tissue Res 2004; 318(1): 225-241. 
[22] Brown, TP, Rumsby PC, Capleton AC, Rushton L, Levy LS. Pesticides and Parkinson's disease--is there a link? Environ Health Perspect 2006; 114(2): 156-64.

[23] Liou HH, Tsai MC, Chen CJ, et al. Environmental risk factors and Parkinson's disease: a case-control study in Taiwan. Neurology 1997; 48(6): 1583-88.

[24] Dinis-Oliveira RJ, Remia o F, Carmo H, et al. Paraquat exposure as an etiological factor of Parkinson's disease. Neurotoxicology 2006; 27(6): 1110-1122.

[25] Shimizu K, Ohtaki K, Matsubara K, et al. Carrier-mediated processes in blood-brain barrier penetration and neural uptake of paraquat. Brain Res 2001; 906(1-2): 135-142.

[26] McCormack AL, Di Monte DA. Effects of L-dopa and other amino acids against paraquat induced nigrostriatal degeneration. J Neurochem 2003; 85(1): 82-86.

[27] Shimizu K, Matsubara K, Ohtaki K, Shiono H. Paraquat leads to dopaminergic neural vulnerability in organotypic midbrain culture. Neurosci Res 2003; 46(4): 523-532.

[28] Clejan L, Cederbaum AI. NADPH-cytochrome P-450 reductase, paraquat, and iron in the generation of active oxygen radicals. Biochem Pharmacol 1989; 38(11): 1779-86.

[29] Fernandez Y, Subirade I, Anglade F, Periquet A, Mitjavila S. Microsomal membrane peroxidation by an $\mathrm{Fe}^{3+} /$ Paraquat system. Consequences of phenobarbital induction. Biol Trace Elem Res 1995; 47(1-3): 9-15.

[30] Fukushima T, Yamada K, Isobe A, Shiwaku K, Yamane Y. Mechanism of cytotoxicity of paraquat. I. NADH oxidation and paraquat radical formation via complex I. Exp Toxicol Pathol 1993; 45(5-6): 345-349.

[31] Castello PR, Drechsel DA, Patel M. Mitochondria are a major source of paraquat-induced reactive oxygen species production in the brain. J Biol Chem 2007; 282(19): 14186-93.

[32] McCarthy S, Somayajulu M, Sikorska M, Borowy-Borowski H, Pandey S. Paraquat induces oxidative stress and neuronal cell death; neuroprotection by water-soluble Coenzyme Q10. Toxicol Appl Pharmacol 2004; 201(1): 21-31.

[33] Betarbet R, Sherer TB, MacKenzie G, Garcia-Osuna M, Panov AV, Greenamyre JT. Chronic systemic pesticide exposure reproduces features of Parkinson's disease. Nat Neurosci 2000; 3(12): 1301-6.

[34] Greenamyre JT, Betarbet R, Sherer TB. The rotenone model of Parkinson's disease: genes, environment and mitochondria. Parkinsonism Relat Disord 2003; 9(2): S59-S64.

[35] Sherer TB, Betarbet R, Testa CM, et al. Mechanism of toxicity in rotenone models of Parkinson's disease. J Neurosci 2003; 23(34): 10756-10764.

[36] Hensley K, Pye QN, Maidt ML, et al. Interaction of a-phenyl-Ntert-butyl nitrone and alternative electron acceptors with complex I indicates a substrate reduction site upstream from the rotenone binding site. J Neurochem 1998; 71(6): 2549-2557.

[37] Kim WG, Mohney RP, Wilson B, Jeohn GH, Liu B, Hong JS. Regional difference in susceptibility to lipopolysaccharide-induced neurotoxicity in the rat brain: role of microglia. J Neurosci 2000; 2(0(16): 6309-6316.

[38] Thiruchelvam M, McCormack A, Richfield EK, et al. Age-related irreversible progressive nigrostriatal dopaminergic neurotoxicity in the paraquat and maneb model of the Parkinson's disease phenotype. Eur J Neurosci 2003; 18(3): 589-600.

[39] Gorell JM, Johnson, CC, Rybicki BA, Peterson EL, Kortsha GX, Brown GG, Richardson RJ. Occupational exposure to manganese, copper, lead, iron, mercury and zinc and the risk of Parkinson's disease. Neurotoxicology 1999; 20(2-3): 239-47.

[40] Dexter DT, Wells FR, Lees AJ, et al. Increased nigral iron content and alterations in other metal ions occurring in brain in Parkinson's disease. J Neurochem 1989; 52(6): 1830-36.

[41] Hirsch EC, Brandel JP, Galle P, Javoy-Agid F, Agid Y. Iron and aluminum increase in the substantia nigra of patients with Parkinson's disease: an X-ray microanalysis. J Neurochem 1991; 56(2): 446-51.

[42] Uversky VN, Li J, Fink AL. Metal-triggered structural transformations, aggregation, and fibrillation of human $\alpha$-synuclein. J Biol Chem 2001; 276(47): 44284-44296.

[43] Koller WC, Cersosimo MG. Neuroprotection in Parkinson's disease: an elusive goal. Curr Neurol Neurosci Rep 2004; 4(4): 277 283.
[44] Dringen, R. Metabolism and functions of glutathione in the brain. Prog Neurobiol 2000; 62: 649-671.

[45] Jenner P. Oxidative stress in Parkinson's disease. Ann Neurol 2003; 53(3): S26-36; discussion S36-8.

[46] Spina M, Cohen G. Exposure of striatal [corrected] synaptosomes to L-dopa increases levels of oxidized glutathione. J Pharmacol Exp Ther 1988; 247(2): 502-7. Erratum in: J Pharmacol Exp Ther 1989; 248: 478.

[47] Sofic E, Paulus W, Jellinger K, Riederer P, Youdim MB. Selective increase of iron in substantia nigra zona compacta of parkinsonian brains. J Neurochem 1991; 56(3): 978-82.

[48] Jellinger KA, Kienzl E, Rumpelmaier G, et al. Iron and ferritin in substantia nigra in Parkinson's disease. Adv Neurol 1993; 60: 267 72.

[49] Andersen JK. Oxidative stress in neurodegeneration: cause or consequence? Nat Med 2004; 10(1): S18-S25.

[50] Sanchez-Ramos JR, Overik E, Ames BN. A marker of oxyradicalmediated DNA damage (8-hydroxy-2'deoxyguanosine) is increased in the nigro-striatum of Parkinson's disease brain. Neurodegeneration 1994; 3(3): 197-204.

[51] Yoritaka A, Hattori N, Uchida K, Tanaka M, Stadtman ER, Mizuno Y. Immunohistochemical detection of 4-hydroxynonenal protein adducts in Parkinson disease. Proc Natl Acad Sci USA 1996; 93: $2696-2701$.

[52] Floor E, Wetzel MG. Increased protein oxidation in human substantia nigra pars compacta in comparison with basal ganglia and prefrontal cortex measured with an improved dinitrophenylhydrazine assay. J Neurochem 1998; 70(1): 268-275.

[53] Alam ZI, Daniel SE, Lees AJ, Marsden DC, Jenner P, Halliwell B. A generalised increase in protein carbonyls in the brain in Parkinson's but not incidental Lewy body disease. J Neurochem 1997; 69(3): 1326-1329.

[54] Alam ZI, Jenner A, Daniel SE, et al. Oxidative DNA damage in the parkinsonian brain: an apparent selective increase in 8-hydroxyguanine levels in substantia nigra. J Neurochem 1997; 69(3): 11961203.

[55] Zhang J, Perry G, Smith MA, et al. Parkinson's disease is associated with oxidative damage to cytoplasmic DNA and RNA in substantia nigra neurons. Am J Pathol 1999; 154(5): 1423-1429.

[56] Beal MF. Mitochondria, oxidative damage and Inflammation in Parkinson's Diseases. Ann N Y Acad Sci 2003; 991: 120-131.

[57] Perry TL, Godin DV, Hansen S. Parkinson's disease: a disorder due to nigral glutathione deficiency? Neurosci Lett 1982; 33(3): 30510 .

[58] Perry TL, Yong VW, Wall RA, Jones K. Idiopathic Parkinson's disease, progressive supranuclear palsy and glutathione metabolism in the substantia nigra of patients. Neurosci. Lett 1986; 67(3): 26974.

[59] Riederer P, Sofic E, Rausch WD, et al. Transition metals, ferritin, glutathione, and ascorbic acid in parkinsonian brains. J Neurochem 1989; 52(2): 515-20.

[60] Nakamura K, Wang W, Kang UJ. The role of glutathione in dopaminergic neuronal survival. J Neurochem 1997; 69: 1850-1858.

[61] Savitt JM, Dawson VL, Dawson TM. Diagnosis and treatment of Parkinson's disease: molecules to medicine. J Clin Invest 2006; 116(7): 1744-54.

[62] Sun F, Kanthasamy A, Vellareddy A, Kanthasamy AG. Environmental neurotoxic chemicals-induced ubiquitin proteasome system dysfunction in the pathogenesis and progression of Parkinson's disease. Pharmacol Ther 2007; 114(3): 327-344.

[63] Betarbet R, Sherer BT, Greenamyre T. Ubiquitin-proteasome system and Parkinson's diseases. J Exp Neurol 2005; 19: S17-S27.

[64] McNaught KS, Björklund LM, Belizaire R, Isacson O, Jenner P, Olanow CW. Proteasome inhibition causes nigral degeneration with inclusion bodies in rats. Neuroreport 2002; 13(11): 1437-41.

[65] Schapira AH. Mitochondria in the aetiology and pathogenesis of Parkinson's disease. Lancet Neurol 2008; 7(9): 97-109

[66] Youdim MB, Ben Shachar D, Riederer P. Is Parkinson's disease a progressive siderosis of substantia nigra resulting in iron and melanin induced neurodegeneration? Acta Neurol Scand Suppl 1989; 126: 47-54.

[67] Shergill JK, Cammack R, Cooper CE, Cooper JM, Mann VM, Schapira AH. Detection of nitrosyl complexes in human substantia 
nigra, in relation to Parkinson's disease. Biochem Biophys Res Commun 1996; 228(2): 298-305.

[68] Beckman JS, Beckman TW, Chen J, Marshall PA, Freeman BA. Apparent hydroxyl radical production by peroxynitrite: implications for endothelial injury from nitric oxide and superoxide. Proc Natl Acad Sci USA 1990; 87(4): 1620-1624.

[69] Reif DW, Simmons RD. Nitric oxide mediates iron release from ferritin. Arch Biochem Biophys 1990; 283(2): 537-541.

[70] Barker JE, Heales SJ, Cassidy A, Bolaños JP, Land JM, Clark, JB. Depletion of brain glutathione results in a decrease of glutathione reductase activity; an enzyme susceptible to oxidative damage. Brain Res 1996; 716(1-2): 118-122.

[71] Mizuno Y, Ohta S, Tanaka M, et al. Deficiencies in complex I subunits of the respiratory chain in Parkinson's disease. Biochem. Biophys Res Commun 1989; 163(3): 1450-5.

[72] Schapira AH, Cooper JM, Dexter D, Clark JB, Jenner P, Marsden CD. Mitochondrial complex I deficiency in Parkinson's disease. J Neurochem 1990; 54(3): 823-7.

[73] Fukae J, Noda K, Fujishima K, et al. Mitochondrial dysfunction in Parkinson's disease. Mitochondrion 2007; 7(1-2): 58-62.

[74] Bolanos JP, Heales SJ, Peuchen S, Barker JE, Land JM, Clark JB. Nitric oxide-mediated mitochondrial damage: a potential neuroprotective role for glutathione. Free Radic Biol Med 1996; 21(7): 9951001.

[75] Henchcliffe C, Beal M F. Excitotoxicity. Handbook of clinical neurology, 2007; vol. 83 (3rd series) Parkinson's disease and related disorders, part I, Chapter 27:553-569.

[76] Feger J, Hassani LN, Mouroux M. The subthalamic nucleus and its connections new electrophysiological and pharmacological data. Adv Neurol 1997; 74:31-43.

[77] Rodriguez MC, Obeso JA, Olanow CW. Subthalamic nucleusmediated excitotoxicity in Parkinson's disease: a target for neuroprotection. Ann Neurol 1998; 44(3 Suppl 1): S175-88.

[78] Turski L, Bressler K, Rettig KJ, Löschmann PA, Wachtel H. Protection of substantia nigra from $\mathrm{MPP}^{+}$neurotoxicity by $N$-methylD-aspartate antagonists. Nature 1991; 349(6308): 414-418.

[79] Uitti RJ, Rajput AH, Ahlskog JE, et al. Amantadine treatment is an independent predictor of improved survival in Parkinson's disease. Neurology 1996; 46(6): 1551-6.

[80] McGeer PL, Itagaki S, Boyes BE, McGeer EG. Reactive microglia are positive for HLA DR in the substantia nigra of Parkinson's and Alzheimer's disease brains. Neurology 1988; 38(8): 1285-1291.

[81] Czlonkowska A, Kohutnicka M, Kurkowska-Jastrzebska I, Czlonkowski A. Microglial reaction in MPTP (1-methyl-4-phenyl1,2,3,6-tetrahydropyridine) induced Parkinson's disease mice brain. Neurodegeneration 1996; 5(2): 137-43.

[82] McNaught KS, Jenner P. Altered glial function causes neuronal death and increases neuronal susceptibility to 1-methyl-4-phenylpyridinium- and 6-hydroxydopamine-induced toxicity in astrocytic/ventral mesencephalic co-cultures. J Neurochem 1999; 73(6): 2469-76.

[83] Teismann P, Schulz JB. Cellular pathology of Parkinson's disease: astrocytes, microglia and inflammation. Cell Tissue Res 2004; 318(1): 149-161.

[84] McGeer EG, McGeer PL. Brain inflammation in Alzheimer disease and the therapeutic implications. Curr Pharm Des 1999; 5(10): 82136.

[85] Kreutzberg GW. Microglia: a sensor for pathological events in the CNS. Trends Neurosci 1996; 19(8): 312-318.

[86] Babior BM. NADPH oxidase: an update. Blood 1999; 93(5): 14641476.

[87] Hastings TG. Enzymatic oxidation of dopamine: the role of prostaglandin H synthase. J Neurochem 1995; 64(2): 919-924.

[88] Mogi M, Harada M, Riederer P, Narabayashi H, Fujita K, Nagatsu T. Tumor necrosis factor- $\alpha$ (TNF- $\alpha$ ) increases both in the brain and in the cerebrospinal fluid from parkinsonian patients. Neurosci Lett 1994; 165(1-2): 208-210.

[89] Hartmann A, Troadec JD, Hunot S, et al. Caspase-8 is an effector in apoptotic death of dopaminergic neurons in Parkinson's disease, but pathway inhibition results in neuronal necrosis. $\mathrm{J}$ Neurosci 2001; 21(7): 2247-2255.

[90] Hartmann A, Hunot S, Michel PP, et al. Caspase-3: a vulnerability factor and final effector in apoptotic death of dopaminergic neurons in Parkinson's disease. Proc Natl Acad Sci USA 2000; 97(6): 28752880.

[91] Forno LS, DeLanney LE, Irwin I, Di Monte D, Langston JW. Astrocytes and Parkinson's disease. Prog Brain Res 1992; 94: 429436.

[92] Damier P, Hirsch EC, Zhang P, Agid Y, Javoy-Agid F. Glutathione peroxidase, glial cells and Parkinson's disease. Neuroscience 1993; 52(1): 1-6.

[93] Wakabayashi K, Hayashi S, Yoshimoto M, Kudo H, Takahashi H. $\mathrm{NACP} / \alpha$-synuclein-positive filamentous inclusions in astrocytes and oligodendrocytes of Parkinson's disease brains. Acta Neuropathol 2000; 99: 14-20.

[94] Khandahar SM, Marks WJ. Epidemiology of Parkinson's disease. Dis Mon 2007; 53(4): 200-205.

[95] Wirdefeldt K, Gatz M, Pawitan Y, Pedersen NL. Risk and protective factors for Parkinson's disease: a study in Swedish twins. Ann Neurol 2005; 57(1): 27-33.

[96] Logroscino G. The role of early life environmental risk factors in Parkinson's disease: what is the evidence? Environ Health Perspect 2005; 113(9): 1234-1238.

[97] Rajput AH, Birdi S. Epidemiology of Parkinson's Disease Source. Parkinsonism Relat Disord 1997; 3(4): 175-186.

[98] Baumann R, Jameson HD, McKean HE, Haak DG, Weisberg LM. Cigarette smoking and Parkinson's disease. 1. A comparison of cases with matched neighbors. Neurology 1980; 30(8): 839-843.

[99] Haack DG, Bauman RJ, McKean HE, Jameson HD, Turbeck JA. Nicotine exposure in Parkinson's disease. Am J Epidemiol 1981; 114(2): 191-200.

[100] Grandinetti A, Morens DM, Reed D, MacEachern D. Prospective study of cigarette smoking and the risk of developing idiopathic Parkinson's disease. Am J Epidemiol 1994; 139(12): 1129-1138.

[101] Allam MF, Del Castillo AS, Navajas RFC. Smoking and Parkinson's disease. Eur J Neurol 2002; 9(3): 315-322.

[102] Checkoway H, Powers K, Smith-Weller T, Franklin GM, Longstreth WT Jr, Swanson PD. Parkinson's disease risks associated with cigarette smoking, alcohol consumption, and caffeine intake. Am J Epidemiol 2002;155(8): 732-8.

[103] Schwarzschild MA, Chen J-F, Ascherio A. Caffeinated clues and the promise of adenosine $A_{2 A}$ antagonists in PD. Neurology 2002; 58(8): 1154-1160.

[104] Benedetti MD, Bower JH, Maraganore DM, et al. Smoking, alcohol, and coffee consumption preceding Parkinson's disease. A case-control study. Neurology 2000; 55: 1350-1358.

[105] Tanner CM, Aston DA. Epidemiology of Parkinson's disease and akinetic syndromes. Curr Opin Neurol 2000; 13(4): 427-430.

[106] Li X, Sundquist J, Hwang H, Sundquist K. Impact of psychiatric disorders on Parkinson's disease: a nationwide follow-up from Sweden. J Neurol 2007; 255(1): 1432-1459.

[107] Taylor S E. (2006) Health Psychology (6 ${ }^{\text {th }}$ Edition) New York: McGraw Hill.

[108] Nuti A, Ceravolo R, Piccinni A, et al. Psychiatric comorbidity in a population of Parkinson's disease patients. Eur J Neurol 2004; 11(5): 315-320.

[109] Stein MB, Heuser IJ, Juncos JL, Uhde TW. Anxiety disorders in patients with Parkinson's disease. Am J Psychiatry 1990; 147(2): 217-220.

[110] Vazquez A, Jimenez-Jimenez FJ, Garcia-Ruiz P, Garcia-Urra D. Panic attacks in Parkinson's disease. A long-term complication of levodopa therapy. Acta Neurol Scand 1993; 87(1): 14-18.

[111] Lauterbach EC, Duvoisin RC. Anxiety disorders in familial parkinsonism. Am J Psychiatry 1991; 148(2): 274.

[112] Menza MA, Mark MH. Parkinson's disease and depression: the relationship to disability and personality. J Neuropsychiatry Clin Neurosci 1994; 6(2): 165-169.

[113] Weisskopf MG, Chen H, Schwarzschild MA, Kawachi I, Ascherio A. Prospective study of phobic anxiety and risk of Parkinson's disease. Mov Disord 2003; 18(6): 646-651.

[114] Rajput AH, Offord KP, Beard CM, Kurland LT. A case-control study of smoking habits, dementia, and other illnesses in idiopathic Parkinson's disease. Neurology 1987; 37(2): 226-232.

[115] Shiba M, Bower JH, Maraganore DM, et al. Anxiety disorders and depressive disorders preceding Parkinson's disease: a case-control study. Mov Disord 2000; 15(4): 669-677. 
[116] Mayeux R, Stern Y, Williams JB, Cote L, Frantz A, Dyrenfurth I. Clinical and biochemical features of depression in Parkinson's disease. Am J Psychiatry 1986; 146(6): 756-759.

[117] German DC, Manaye KF, White CL. Disease-specific patterns of locus coeruleus cell loss. Ann Neurol 1992; 32(5): 667-676.

[118] Schuurman AG, Van den Akker M, Ensinck KTJL, et al. Increased risk of Parkinson's disease after depression. Neurology 2002; 58 (10): 1501-1504.

[119] Martignoni E, Verri AP, Nappi G. Parkinson's disease and depression: one disease? Eur Neuropsychopharmacol 1995; 5(3): 246.

[120] Leentjens AFG. Depression in Parkinson's disease: conceptual issues and clinical challenges. J Geriatr Psychiatry Neurol 2004; 17(3): 120-126.

[121] Kuopio AM, Marttila RJ, Helenius H, Rinne UK. Environmental risk factors in Parkinson's disease. Mov Disord 1999; 14(6): 928939.

[122] Wang W, Fang X, Cheng X, Jiang D, Lin Z. A case-control study on the environmental risk factors of Parkinson's disease in Tianjin, China. Neuroepidemiology 1993; 12(4): 209-218.

[123] Schaie W, Lawton MP. Annu Rev Gerontol Geriatr. Springer: New York 1998.

[124] Hartmann A, Veldhuis JD, Deuschile M, Standhardt H, Heuser I. Twenty-four hour cortisol release profiles in patients with Alzheimer's and Parkinson's disease compared to normal controls: ultradian secretory pulsatility and diurnal variation. Neurobiol Aging 1997; 18(3): 285-289.

[125] Gale CR, Braidwood EA, Winter PD, Martyn CN. Mortality from Parkinson's disease and other causes in men who were prisoners of war in the Far East. Lancet 1999; 354(9196): 2116-2118.

[126] Page WF, Tanner CM. Parkinson's disease and motor-neuron disease in former prisoners-of-war. Lancet 2000; 355(9206): 843.

[127] Howells FM, Russell VA, Mabandla MV, Kellaway LA. Stress reduces the neuroprotective effect of exercise in a rat model of Parkinson's disease. Behav Brain Res 2005; 165(2): 210-220.

[128] Logroscino G, Sesso HD, Paffenbarger RS Jr, Lee IM. Physical activity and risk of Parkinson's disease: a prospective cohort study. J Neurol Neurosurg Psychiatry 2006; 77(12): 1318-1322.

[129] Williams DB, Annegers JF, Kokmen E, Obrien PC, Kurland LT. Brain injury and neurologic sequelae - a cohort study of dementia, parkinsonism, and amyotrophic-lateral-sclerosis. Neurology 1991; 41(10): 1554-1557.

[130] Semchuk KM, Love EJ, Lee RG. Parkinson's disease: a test of the multifactorial etiologic hypothesis. Neurology 1993; 43(6): 11731180.

[131] De Michele G, Filla A, Volpe G, et al. Environmental and genetic risk factors in Parkinson's disease: a case-control study in southern Italy. Mov Disord 1996; 11(1): 17-23.

[132] Goldman SM, Tanner CM, Oakes D, Bhudhikanok GS, Gupta A, Langston JW. Head injury and Parkinson's disease risk in twins. Ann Neurol 2006; 60(1): 65-72.

[133] Beal MF. Bioenergetic approaches for neuroprotection in Parkinson's disease. Ann Neurol 2003; 53(3): 539-548.

[134] Beal MF, Shults CW. Effects of Coenzyme Q10 in Hungtington's disease and early Parkinson's disease. BioFactors 2003; 18(1-4): 153-161.

[135] Sandhu JK, Pandey S, Ribecco-Lutkiewicz M, Monette R, BorowyBorowski H, Walker P, Sikorska M. Molecular mechanisms of glutamate neurotoxicity in mixed cultures of NT2-derived neurons and astrocytes: protective effects of coenzyme Q10. J Neurosci Res 2003; 72(6): 691-703.

[136] Naderi J, Somayajulu-Nițu M, Mukerji A, et al. Water-soluble formulation of Coenzyme $\mathrm{Q}_{10}$ inhibits Bax-induced destabilization of mitochondria in mammalian cells. Apoptosis 2006; 11(8): 135969.

[137] Hampel H, Goernitz A, Buerger K. Advances in the development of biomarkers for Alzheimer's disease: from CSF total tau and $\mathrm{A} \beta_{1-}$ 42 proteins to phosphorylated tau protein. Brain Res Bull 2003; 61(3): 243-53.

[138] Cecchi C, Latorraca S, Sorbi S, et al. Gluthatione level is altered in lymphoblasts from patients with familial Alzheimer's disease. Neurosci Lett 1999; 275(2): 152-154.

[139] Zhu X, Raina AK, Perry G, Smith MA. Alzheimer's disease: the two-hit hypothesis. Lancet Neurol 2004; 3(4): 219-226.
[140] Nunomura A, Perry G, Pappolla MA, et al. Neuronal oxidative stress precedes amyloid- $\beta$ deposition in Down syndrome. J Neuropathol Exp Neurol 2000; 59(11): 1011-17.

[141] Smith MA, Sayre LM, Monnier VM, Perry G. Radical aging in Alzheimer's disease. Trends Neurosci 1995; 18(4): 172-76.

[142] Nunomura A, Perry G, Aliev G, et al. Oxidative damage is the earliest event in Alzheimer's disease. J Neuropathol Exp Neurol 2001; 60(8): 759-67.

[143] Castegna A, Thongboonkerd V, Klein JB, Lynn B, Markesbery WR, Butterfield DA. Proteomic identification of nitrated proteins in Alzheimer's disease brain. J Neurochem 2003; 85(6): 1394-401.

[144] Cras P, Smith MA, Richey PL, Siedlak SL, Mulvihill P, Perry G. Extracellular neurofibrillary tangles reflect neuronal loss and provide further evidence of extensive protein cross-linking in Alzheimer's disease. Acta Neuropathol 1995; 89(4): 291-95.

[145] Markesbery WR, Lovell MA. Four-hydroxynonenal, a product of lipid peroxidation, is increased in the brain in Alzheimer's disease. Neurobiol Aging 1998; 19(1): 33-36.

[146] Lovell MA, Ehmann WD, Butler SM, Markesbery WR. Elevated thiobarbituric acid reactive substances and antioxidant enzyme activity in the brain in Alzheimer's disease. Neurology 1995; 45(8): 1594-601.

[147] Tamaoka A, Miyatake F, Matsuno S, et al. Apolipoprotein E alleledependent antioxidant activity in brains with Alzheimer's disease. Neurology 2000; 54(12): 2319-21.

[148] Palmer AM, Burns MA. Selective increase in lipid peroxidation in the inferior temporal cortex in Alzheimer's disease. Brain Res 1999; 645(1-2): 338-42.

[149] Guan Z, Wang Y, Cairns NJ, Lantos PL, Dallner G, Sindelar PJ. Decrease and structural modifications of phosphatidylethanolamine plasmalogen in the brain with Alzheimer's disease. J Neuropathol Exp Neurol 1999; 58(7): 740-47.

[150] Nunomura A, Perry G, Pappolla MA, et al. RNA oxidation is a prominent feature of vulnerable neurons in Alzheimer's disease. J Neurosci 1999; 19(6): 1959-64.

[151] Colurso GJ, Nilson JE, Vervoort LG. Quantitative assessment of DNA fragmentation and beta-amyloid deposition in insular cortex and midfrontal gyrus from patients with Alzheimer's disease. Life Sci 2003; 73(14): 1795-803.

[152] Adamec E, Vonsattel JP, Nixon RA. DNA strand breaks in Alzheimer's disease. Brain Res 1999; 849(1-2): 67-77.

[153] Castellani RJ, Harris PL, Sayre LM, et al. Active glycation in neurofibrillary pathology of Alzheimer's disease: $\mathrm{N}^{\varepsilon}$-(carboxymethyl) lysine and hexitol-lysine. Free Radic Biol Med 2001; 31(2): 17580 .

[154] Aksenov MY, Tucker HM, Nair P, et al. The expression of key oxidative stress-handling genes in different brain regions in Alzheimer's disease. J Mol Neurosci 1998; 11(2): 151-64.

[155] Mielke K, Herdegen T. JNK and p38 stress kinases: degenerative effectors of signal-transduction cascades in the nervous system. Prog Neurobiol 2000; 61(1): 45-60.

[156] Zhu X, Raina AK, Rottkamp CA, et al . Activation and redistribution of c-Jun N-terminal kinase/stress activated protein kinase in degenerating neurons in Alzheimer's disease. J Neurochem 2001; 76(2): 435-41.

[157] Pappolla MA, Omar RA, Kim KS, Robakis NK. Immunohistochemical evidence of oxidative [corrected] stress in Alzheimer's disease. Am J Pathol 1992; 140: 621-28.

[158] Zhu X, Su B, Wang X, Smith MA, Perry G. Causes of oxidative stress in Alzheimer's disease. Cell Mol Life Sci 2007; 64(17): 2202-10.

[159] Blass JP. The mitochondrial spiral: an adequate cause of dementia in the Alzheimer's syndrome. Ann NY Acad Sci 2000; 924: 170183.

[160] Fukuyama H, Ogawa M, Yamauchi H, et al. Altered cerebral energy metabolism in Alzheimer's disease: a PET study. J Nucl Med 1994; 35(1): 1-6.

[161] Smith MA, Casadesus G, Joseph JA, Perry G. Amyloid- $\beta$ and $\tau$ serve antioxidant functions in the aging and Alzheimer brain. Free Radic Biol Med 2002; 33(9): 1194-1199.

[162] Kamenetz F, Tomita T, Hsieh H, et al. APP processing and synaptic function. Neuron 2003; 37(6): 925-937.

[163] Rottkamp CA, Raina AK, Zhu X, et al. Redox-active iron mediates amyloid-ß toxicity. Free Radic Biol Med 2001; 30(4): 447-450. 
[164] Unnikrishnan MK, Rao MN. Antiinflammatory activity of methionine, methionine sulfoxide and methionine sulfone. Agents Actions 1990; 31(1-2): 110-112.

[165] Hiller K-O, Asmus K-D. $\mathrm{Tl}^{2+}$ and $\mathrm{Ag}^{2+}$ metalion- induced oxidation of methionine in aqueous solution: a pulse radiolysis study. Int $\mathbf{J}$ Radiat Biol 1981; 40(6): 597-604.

[166] Iversen LL, Mortishire-Smith RJ, Pollack SJ, Shearman MS. The toxicity in vitro of B-amyloid protein. Biochem J 1995; 311(1): 116.

[167] Varadarajan S, Yatin S, Aksenova M, Butterfield DA. Review: Alzheimer's amyloid ß-peptide associated free radical oxidative stress and neurotoxicity. J Struct Biol 2000; 130(2-3): 184-208.

[168] Kontush A, Berndt C, Weber W, et al. Amyloid- $\beta$ is an antioxidant for lipoproteins in cerebrospinal fluid and plasma. Free Radic Biol Med 2001; 30(1): 119-128.

[169] Behl C, Davis JB, Lesley R, Schubert D. Hydrogen peroxide mediates amyloid ß protein toxicity. Cell 1994; 77(6): 817-827.

[170] Mark RJ, Lovell MA, Markesbery WR, Uchida K, Mattson MP. A role for 4-hydroxynonenal, an aldehydic product of lipid peroxidation, in disruption of ion homeostasis and neuronal death induced by amyloid B-peptide. J Neurochem 1997; 68(1): 255-264.

[171] Mark RJ, Pang Z, Geddes JW, Uchida K, Mattson MP. Amyloid Bpeptide impairs glucose transport in hippocampal and cortical neurons: involvement of membrane lipid peroxidation. J Neurosci 1997; 17(3): 1046-1054.

[172] Xu J, Chen S, Ahmed SH, et al. Amyloid-beta peptides are cytotoxic to oligodendrocytes. J Neurosci 2001; 21(1): RC118.

[173] Blass JP, Gibson GE. Cerebrometabolic aspects of delirium in relationship to dementia. Dement Geriatr Cogn Disord 1999; 10(5): 335-38.

[174] Castellani R, Hirai K, Aliev G, et al. Role of mitochondrial dysfunction in Alzheimer's disease. J Neurosci Res 2002; 70(3): 357360 .

[175] Gibson GE, Sheu KF, Blass JP. Abnormalities of mitochondrial enzymes in Alzheimer disease. J Neural Transm 1998; 105(8-9): 55-870.

[176] de la Torre JC. Cerebromicrovascular pathology in Alzheimer's disease compared to normal aging. Gerontology 1997; 43(1-2): 2643.

[177] Coskun PE, Beal MF, Wallace DC. Alzheimer's brains harbor somatic mtDNA control-region mutations that suppress mitochondrial transcription and replication. Proc Natl Acad Sci USA 2004; 101(29): 10726-10731.

[178] Seshadri S, Beiser A, Selhub J, et al. Plasma homocysteine as a risk factor for dementia and Alzheimer's disease. N Engl J Med 2002; 346(7): 476-483.

[179] Streck EL, Matte C, Vieira PS, et al. Impairment of energy metabolism in hippocampus of rats subjected to chemically-induced hyperhomocysteinemia. Biochim Biophys Acta 2003; 1637(3): 187192.

[180] Smith MA, Harris PL, Sayre LM, Perry G. Iron accumulation in Alzheimer disease is a source of redox generated free radicals. Proc Natl Acad Sci USA 1997; 94(18): 9866-9868.

[181] Smith MA, Richey Harris PL, Sayre LM, Beckman JS, Perry G. Widespread peroxynitrite-mediated damage in Alzheimer's disease. J Neurosci 1997; 17(8): 2653-2657.

[182] Honda K, Smith MA, Zhu X, et al. Ribosomal RNA in Alzheimer disease is oxidized by bound redox-active iron. J Biol Chem 2005; 280(22): 20978-20986.

[183] Loeffler DA, LeWitt PA, Juneau PL, et al. Increased regional brain concentrations of ceruloplasmin in neurodegenerative disorders. Brain Res 1996; 738(2): 265 -274.

[184] Castellani RJ, Smith MA, Nunomura A, Harris PL, Perry G. Is increased redox-active iron in Alzheimer disease a failure of the copper-binding protein ceruloplasmin? Free Radic Biol Med 1999; 26(11-12): 1508-1512.

[185] Harrington CR, Colaco CA. Alzheimer's disease: a glycation connection. Nature 1994; 370(6487): 247-248.

[186] Münch G, Thome J, Foley P, Schinzel R, Riederer P. Advanced glycation endproducts in ageing and Alzheimer's disease. Brain Res Rev 1997; 23(1-2): 134-143.

[187] Vitek MP, Bhattacharya K, Glendening JM, et al. Advanced glycation end products contribute to amyloidosis in Alzheimer disease. Proc Natl Acad Sci USA 1994; 91(11): 4766-4770.
[188] Ko L-W, Ko EC, Nacharaju P, et al. An immunochemical study on tau glycation in paired helical filaments. Brain Res 1999; 830(2): 301-313.

[189] Mruthinti S, Sood A, Humphrey CL, Swamy-Mruthinti S, Buccafusco J J. The induction of surface beta amyloid binding proteins and enhanced cytotoxicity in cultured PC-12 and IMR-32 cells by advanced glycation end products. Neuroscience 2006; 142(2): 463 473.

[190] El Khoury J, Hickman SE, Thomas CA, Cao L, Silverstein SC, Loike JD. Scavenger receptor mediated adhesion of microglia to Bamyloid fibrils. Nature 1996; 382(6593): 716-719.

[191] Yan SD, Chen X, Fu J, et al. RAGE and amyloid-beta peptide neurotoxicity in Alzheimer's disease. Nature 1996; 382(6593): 685-691.

[192] Reinheckel T, Ullrich O, Sitte N, Grune T. Differential impairment of $20 \mathrm{~S}$ and $26 \mathrm{~S}$ proteasome activities in human hematopoietic K562 cells during oxidative stress. Arch Biochem Biophys 2000; 377(1): 65-68.

[193] Keller JN, Gee J, Ding Q. The proteasome in brain aging. Ageing Res Rev 2002; 1(2): 279-293.

[194] Keller JN, Hanni KB, Markesbery WR. Impaired proteasome function in Alzheimer's disease. J Neurochem 2000; 75(1): 36-439.

[195] Akiyama H, Barger S, Barnum S, et al. Inflammation and Alzheimer's disease. Neurobiol Aging 2000; 21(3): 383-421.

[196] Klegeris A, McGeer PL. B-Amyloid protein enhances macrophage production of oxygen free radicals and glutamate. J Neurosci Res 1997; 49(2): 229-235.

[197] Reynolds WF, Rhees J, Maciejewski D, et al. Myeloperoxidase polymorphism is associated with gender specific risk for Alzheimer's disease. Exp Neurol 1999; 155(1): 31-41.

[198] Cecchi C, Fiorillo C, Sorbi S, et al. Oxidative stress and reduced antioxidant defenses in peripheral cells from familial Alzheimer's patients. Free Radic Biol Med 2002; 33(10): 1372-9.

[199] Migliore L, Fontana I, Trippi F, et al. Oxidative DNA damage in peripheral leukocytes of mild cognitive impairment and AD patients. Neurobiol Aging 2005; 26(5): 567-573.

[200] Mecocci P, Polidori C, Cherubini A, et al. Lympocyte oxidative DNA damage and plasma antioxidants in Alzheimer's disease. Arch Neurol 2002; 59(5): 791-8.

[201] Naderi J, Lopez C, Pandey S. Chronically increased oxidative stress in fibroblasts from Alzheimer's disease patients causes early senescence and renders resistance to apoptosis by oxidative stress. Mech Ageing Dev 2006; 127(1): 25-35.

[202] Rinaldi P, Polidori MC, Metastasio A, et al. Plasma antioxidants are similarly depleted in mild cognitive impairment and in Alzheimer's disease. Neurobiol Aging 2003; 24(7): 915-9.

[203] Chaston TB, Richardson DR. Iron chelators for the treatment of iron overload disease: relationship between structure, redox activity, and toxicity. Am J Hematol 2003; 73(3): 200-210.

[204] Whitnall M, Richardson DR. Iron: a new target for pharmacological intervention in neurodegenerative diseases. Semin Pediatr Neurol 2006; 13(3): 186-197.

[205] Crapper-McLachlan DR, Dalton AJ, Kruck TP, et al. Intramuscular desferrioxamine in patients with Alzheimer's disease. Lancet 1991; 337(8753): 1304-1308.

[206] Aouad F, Florence A, Zhang Y, et al. Evaluation of new iron chelators and their therapeutic potential. Inorg Chim Acta 2002; 339: 470-480.

[207] Casdorph HR. Chelation therapy: a reappraisal. N Z Med J 1983; 96(724): 66-67.

[208] Cherny RA, Atwood CS, Xilinas ME, et al. Treatment with a copper-zinc chelator markedly and rapidly inhibits beta-amyloid accumulation in Alzheimer's disease transgenic mice. Neuron 2001; 30: 665-676.

[209] Lee J-Y, Friedman JE, Angel I, Kozak A, Koh J-Y. The lipophilic metal chelator DP-109 reduces amyloid pathology in brains of human $\beta$-amyloid precursor protein transgenic mice. Neurobiol Aging 2004; 25(10): 1315-1321.

[210] House E, Collingwood J, Khan A, Korchazkina O, Berthon G, Exley C. Aluminium, iron, zinc and copper influence the in vitro formation of amyloid fibrils of $A \beta_{42}$ in a manner which may have consequences for metal chelation therapy in Alzheimer's disease. J Alzheimers Dis 2004; 6(3): 291-301. 
[211] Rogers JT, Randall JD, Eder PS, et al. Alzheimer's disease drug discovery targeted to the APP mRNA 5'untranslated region. J Mol Neurosci 2002; 19(1-2): 77-82.

[212] Behl C, Moosmann B. Antioxidant neuroprotection in Alzheimer's disease as preventive and therapeutic approach. Free Radic Biol Med 2002; 33(2): 182-191.

[213] Behl C, Davies J, Cole GM, Schubert D. Vitamin E protects nerve cells from amyloid $\beta$ protein toxicity. Biochem Biophys Res Commun 1992; 186(2): 944-950.

[214] Sano M, Ernesto C, Thomas RG, et al. A controlled trial of selegiline, alpha-tocopherol, or both as treatment for Alzheimer's disease. N Engl J Med 1997; 336(17): 1216-1222.

[215] Moosmann B, Behl C. The antioxidant neuroprotective effects of estrogens and phenolic compounds are independent from their estrogenic properties. Proc Natl Acad Sci USA 1999; 96(16): 88678872.

[216] Blum-Degen D, Haas M, Pohli S, et al. Scavestrogens protect IMR 32 cells from oxidative stress-induced cell death. Toxicol Appl Pharmacol 1998; 152(1): 49-55.

[217] Dubal DB, Kashon ML, Pettigrew LC, et al. Estradiol protects against ischemic injury. J Cereb Blood Flow Metabol 1998; 18(11): 1253-1258.

[218] Sagara Y. Induction of reactive oxygen species in neurons by haloperidol. J Neurochem 1998; 71(3): 1002-1012.

[219] Moosmann B, Uhr M, Behl C. Neuroprotective potential of aromatic alcohols against oxidative cell death. FEBS Lett 1997; 413(3): 467-472.

[220] Skaper SD, Fabris M, Ferrari V, Dalle Carbonare M, Leon A. Quercetin protects cutaneous tissue-associated cell types including sensory neurons from oxidative stress induced by glutathione depletion: cooperative effects of ascorbic acid. Free Radic Biol Med 1997; 22(4): 669-678.

[221] Grundman M. Vitamin E and Alzheimer disease: the basis for additional clinical trials. Am J Clin Nutr 2000; 71(2): 630S-636S.

[222] Weyer G, Babej-Dolle RM, Hadler D, Hofmann S, Herrmann WM. A controlled study of 2 doses of idebenone in the treatment of Alzheimer's disease. Neuropsychobiology 1997; 36(2): 73-82.

[223] Gutzmann H, Hadler D. Sustained efficacy and safety of idebenone in the treatment of Alzheimer's disease: update on a 2-year doubleblind multicentre study. J Neural Transm 1998; 54: 301-310.

[224] Pogocki D, Ruman T, Danilczuk M, Danilczuk M, Celuch M, Wałajtys-Rode E. Application of nicotine enantiomers, derivatives and analogues in therapy of neurodegenerative disorders. Eur $\mathbf{J}$ Pharmacol 2007; 563(1-3):18-39.

[225] Levin ED, McClernon FJ, Rezvani AH. Nicotinic effects on cognitive function: behavioral characterization, pharmacological specification, and anatomic localization. Psychopharmacology (Berl) 2006; 184(3-4): 523-539.
[226] Wang HY, Lee DH, D'Andrea MR, Peterson PA, Shank RP, Reitz AB. $\beta$-Amyloid(1-42) binds to $\alpha 7$ nicotinic acetylcholine receptor with high affinity. Implications for Alzheimer's disease pathology. J Biol Chem 2000; 275(8): 5626-5632.

[227] Kihara T, Shimohama S. Alzheimer's disease and acetylcholine receptors. Acta Neurobiol Exp 2004; 64(1): 99-105.

[228] Zeng H, Zhang Y, Peng L-J, et al. Nicotine and Amyloid Formation. Biol Psychiatry 2001; 49(3): 248-257.

[229] Zhang J, Liu Q, Chen Q, et al. Nicotine attenuates the $\beta$-amyloid neurotoxicity through regulating metal homeostasis. FASEB J 2006; 20(8): E399-E408

[230] Schenk D, Barbour R, Dunn W, et al. Immunization with amyloid$B$ attenuates Alzheimer-disease-like pathology in the PDAPP mouse. Nature 1999; 400(6740): 173-177.

[231] Bard F, Cannon C, Barbour R, et al. Peripherally administered antibodies against amyloid $\beta$-peptide enter the central nervous system and reduce pathology in a mouse model of Alzheimer disease. Nat Med 2000; 6(8): 916-919.

[232] Bard F, Barbour R, Cannon C, et al. Epitope and isotype specificities of antibodies to $B$-amyloid peptide for protection against Alzheimer's disease-like neuropathology. Proc Natl Acad Sci USA 2003; 100(4): 2023-2028.

[233] Bacskai BJ, Kajdasz ST, Christie RH, et al. Imaging of amyloid- $\beta$ deposits in brains of living mice permits direct observation of clearance of plaques with immunotherapy. Nat Med 2001; 7(3): 369-372.

[234] DeMattos RB, Bales KR, Cummins DJ, Dodart J-C, Paul SM, Holtzman DM. Peripheral anti-Aß antibody alters CNS and plasma $A$ beta clearance and decreases brain $A \beta$ burden in a mouse model of Alzheimer's disease. Proc Natl Acad Sci USA 2001; 98(15): 8850-8855.

[235] Sutoo D, Akiyama K, Regulation of brain function by exercise, Neurobiol Dis 2003; 13:1-14.

[236] O'Neill MJ, Murray TK, Lakics V, Visanji NP, Duty S. The role of neuronal nicotinic acetylcholine receptors in acute and chronic neurodegeneration. Curr Drug Targets CNS Neurol Disord 2002; 1(4): 399-411.

[237] Quik M, Chen L, Parameswaran N, Xie X, Langston JW, McCallum SE. Chronic oral nicotine normalizes dopaminergic function and synaptic plasticity in 1-methyl-4-phenyl-1,2,3,6tetrahydropyridine-lesioned primates. J Neurosci 2006; 26(17): 4681-9.

[238] O'Reilly EJ, McCullough ML, Chao A, et al. Smokeless tobacco use and the risk of Parkinson's disease mortality. Mov Disord 2005; 20(10): 1383-4.

[239] Radi R. Nitric oxide, oxidants, and protein tyrosine nitration. PNAS 2004; 101(12): 4003-4008 